\title{
Anti-tat Hutat2:Fc mediated protection against tat-induced neurotoxicity and HIV-1 replication in human monocyte-derived macrophages
}

Wen Kang ${ }^{1,2}$, Wayne A Marasco ${ }^{3}$, Hsin-I Tong ${ }^{2}$, Mary Margaret Byron ${ }^{4}$, Chengxiang $\mathrm{Wu}^{2}$, Yingli Shi ${ }^{2}$, Si Sun ${ }^{2}$, Yongtao Sun ${ }^{1 *}$ and Yuanan Lu ${ }^{2^{*}}$

\begin{abstract}
Background: HIV-1 Tat is essential for HIV replication and is also a well-known neurotoxic factor causing HIV-associated neurocognitive disorder (HAND). Currently, combined antiretroviral therapy targeting HIV reverse transcriptase or protease cannot prevent the production of early viral proteins, especially Tat, once HIV infection has been established. HIV-infected macrophages and glial cells in the brain still release Tat into the extracellular space where it can exert direct and indirect neurotoxicity. Therefore, stable production of anti-Tat antibodies in the brain would neutralize HIV-1 Tat and thus provide an effective approach to protect neurons.

Methods: We constructed a humanized anti-Tat Hutat2:Fc fusion protein with the goal of antagonizing HIV-1 Tat and delivered the gene into cell lines and primary human monocyte-derived macrophages (hMDM) by an HIV-based lentiviral vector. The function of the anti-Tat Hutat2:Fc fusion protein and the potential side effects of lentiviral vector-mediated gene transfer were evaluated in vitro.

Results: Our study demonstrated that HIV-1-based lentiviral vector-mediated gene transduction resulted in a high-level, stable expression of anti-HIV-1 Tat Hutat2:Fc in human neuronal and monocytic cell lines, as well as in primary hMDM. Hutat2:Fc was detectable in both cells and supernatants and continued to accumulate to high levels within the supernatant. Hutat2:Fc protected mouse cortical neurons against HIV-1 Tat 86 -induced neurotoxicity. In addition, both secreted Hutat2:Fc and transduced hMDM led to reducing HIV-1 BaL viral replication in human macrophages. Moreover, lentiviral vector-based gene introduction did not result in any significant changes in cytomorphology and cell viability. Although the expression of IL8, STAT1, and IDOI genes was up-regulated in transduced hMDM, such alternation in gene expression did not affect the neuroprotective effect of Hutat2:Fc.

Conclusions: Our study demonstrated that lentivirus-mediated gene transfer could efficiently deliver the Hutat2:Fc gene into primary hMDM and does not lead to any significant changes in hMDM immune-activation. The neuroprotective and HIV-1 suppressive effects produced by Hutat2:Fc were comparable to that of a full-length anti-Tat antibody. This study provides the foundation and insights for future research on the potential use of Hutat2:Fc as a novel gene therapy approach for HAND through utilizing monocytes/macrophages, which naturally cross the blood-brain barrier, for gene delivery.
\end{abstract}

Keywords: Anti-Tat antibody, HIV-1, HIV-associated neurocognitive disorders, Human monocyte-derived macrophages, Lentivirus, Neuroprotection

\footnotetext{
*Correspondence: yongtaos@hotmail.com; yuanan@hawaii.edu

'Department of Infectious Diseases, Tangdu Hospital, The Fourth Military

Medical University, 569 Xinsi Road, Xi'an, Shaanxi 710038, China

${ }^{2}$ Department of Public Health Sciences, John A. Burns School of Medicine,

University of Hawaii, 1960 East-west Road, Honolulu, HI 96822, USA

Full list of author information is available at the end of the article
} 


\section{Background}

HIV-associated neurocognitive disorders (HAND) occur when HIV enters the central nervous system (CNS) and impairs neuronal function involved in cognitions, including memory, learning, attention, problem solving, and decision making [1]. It can be classified into three categories, namely asymptomatic neurocognitive impairment, mild neurocognitive disorder, and HIV-associated dementia [1,2]. Although more severe forms of HAND are rare thanks to the introduction of combined antiretroviral therapy (cART), the prevalence of milder forms continues to increase [3]. Cross-sectional studies showed that neurologic disorders occur in half of HIV1-infected individuals in the era of cART [3-5]. One explanation for the high prevalence of HAND in the cART era is that cART cannot completely inhibit HIV replication in the CNS, which results in persistent HIV replication at low-levels in the brain [1,6-8]. Either prolonged toxic inflammatory activation or the presence of toxic viral products, such as the HIV-1 Tat protein produced by low-level HIV within the CNS, can continue to drive neurodegeneration [1,9]. Although several antiretroviral agents have been found to enter the CNS with higher efficiency, another issue that arises with cART for HAND treatment is the lack of a correlation between the CNS penetration-effectiveness (CPE) index and efficacy of therapy [10]. A recent study has shown that HIV dementia was even worse among affected individuals who received a cART regimen with a high CPE score [11]. Therefore, development of adjuvant therapies for HAND is urgently needed.

Gene therapy is currently being explored for combating HIV-1 infection [12]. There are numerous anti-HIV gene therapy approaches, all of which can be classified into three broad categories: genetic vaccine-based strategies utilizing HIV peptides or gene products [13-15]; RNA-based strategies including anti-sense RNA, RNA decoys (sense RNA), ribozymes, RNA aptamers, mutant tRNA $_{3}{ }^{\text {Lys }}$, small interfering RNAs, and microRNAs [16-19]; and protein-based strategies including transdominant negative proteins, chimeric proteins (fusion proteins), nucleases, anti-infective cellular proteins, single-chain variable fragment intrabodies ( $\mathrm{scFv}$ ), and monoclonal antibodies [17,20-23]. Although a combined approach utilizing both mRNA and protein-based strategies would be more effective for HAND therapy, each strategy should be tested independently. It is presently known that vaccinebased strategies expressing HIV-1 proteins are not suitable for the treatment of HAND since these proteins are neurotoxic. Although RNA-based strategies interfere with intracellular gene expression, they offer no protection against existing extracellular neurotoxic HIV-1 proteins and inflammatory cytokines in the CNS. Therefore, protein-based gene therapy strategies targeting on both the intra- and extra-cellular neurotoxins would be helpful. Based on this hypothesis, we have developed a lentiviral vector-based gene transfer system to deliver the genes of secretory human brain-derived neurotrophic factor and soluble tumor necrosis factor- $\alpha$ receptor:Fc fusion protein into cell lines and primary monocyte-derived macrophages (MDM). These integrated genes could be expressed with high efficiency and have been shown to protect against TNF- $\alpha$ and HIV-1 Tat and gp120-induced neurotoxicity $[24,25]$. However, these two candidates are limited in their ability to inhibit HIV-1 replication directly.

HIV-1 Tat is a conserved non-structural protein that is essential for HIV-1 replication [26]. It can be secreted by HIV-1 infected macrophages and glial cells within the CNS, or easily enter the CNS by crossing the bloodbrain barrier (BBB). Tat functions as a potent neurotoxin causing HAND directly and indirectly in the brain [27-30]. For example, Tat injures neurons directly through the dysregulation of intracellular $\mathrm{Ca}^{2+}$ levels, increasing excitotoxicity, and disinhibiting permeable N-methyl$\mathrm{D}$-aspartate receptors from $\mathrm{Zn}^{2+}$-mediated antagonism [31-33]. In addition, extracellular Tat can cause neuronal damage indirectly by increasing the expression of nitric oxide synthase and the release of toxins including nitric oxide (NO), TNF- $\alpha$, and IL- $1 \beta$ from monocytes, macrophages, glial cells, and brain endothelial cells [28,34-36]. Therefore, any efforts to blunt the Tat effects would be expected to have profound and significant impact in treating HIV neuropathogenesis, decreasing the prevalence of HIV-associated neurological diseases and improving the quality of life of HIV-infected individuals. Previous attempts utilizing retrovirus-mediated gene transfer of a humanized anti-Tat intrabody termed as Hutat2 into CD $4^{+}$ $\mathrm{T}$ cells have shown to successfully inhibit HIV-1 replication in infected mammalian cell lines and transduced $\mathrm{CD}_{4}^{+}$ mononuclear cell populations [37-39]. Furthermore, a recent in vivo study indicated that retrovirus-mediated antiTat scFv Hutat2 transduction increased the relative survival of transduced $\mathrm{CD} 4^{+} \mathrm{T}$ cells infected with chimeric simian immunodeficiency virus/HIV, and was associated with a viral load reduction in one rhesus macaque [22].

This study is designed to explore the protective effects of lentiviral-mediated gene transfer of anti-Tat Hutat2:Fc against Tat-activated viral transcription as well as Tatinduced neurotoxicity. We modified the native anti-Tat Hutat2 sequence and constructed an HIV-1-based lentiviral vector HR-Hutat2, which expresses humanized anti-Tat scFv:Fc fusion protein (Hutat2:Fc) under the control of the human cytomegalovirus (CMV) promoter. This vector was shown to transduce human cell lines of both neuron and monocyte origins, as well as primary human MDMs (hMDM), resulting in the secretion of Hutat2:Fc fusion protein, albeit to varying levels. The secreted Hutat2:Fc was shown to be protective to mouse 
primary neurons that were exposed to HIV-1 Tat. In addition, both secreted Hutat2:Fc and HR-Hutat2transduced hMDM led to prevention from Tat-activated HIV-1 transcription, thus suppressing viral replication and reducing the spread of viral infection in human macrophages. Potential adverse effects due to the lentiviral vector transduction were also evaluated by assessing the expression profiling of 15 macrophage-related functional and regulatory genes using a real-time PCR assay. Our findings lay out the groundwork for future studies using anti-Tat Hutat2 gene-modified MDM as a potential therapeutic strategy for HAND.

\section{Methods}

\section{Animal care}

Balb/c mice were obtained from Dr. Federick Mercier, University of Hawaii at Manoa, USA. All mice were bred and maintained in the animal facility of the University of Hawaii at Manoa following institutional guidelines. All procedures were reviewed and approved by the University of Hawaii Animal Care and Use Committee and conducted according to the Animal Welfare Act and National Institutes of Health guidelines.

\section{Generation and production of the lentiviral vectors}

A transfer plasmid containing an expression cassette for Hutat2:Fc fusion protein was constructed (Additional file 1). Briefly, the gene encoding the anti-HIV-1 Tat scFv Hutat 2 with a leader sequence fused to the hinge domain from the human $I g G 1$ gene and the Fc domain from the human IgG3 gene was commercially synthesized (GeneArt ${ }^{\odot}$, Life Technologies, Grand Island, NY, USA). The synthetic gene was amplified by PCR, using primer pairs containing Xho I and BamH I restriction sites (Additional file 1), and inserted into the backbone of pHR-HB7-IRES-GFP plasmid (generously provided by Dr. V. Planelles, University of Utah) that was digested with the same enzymes. The final bicistronic plasmid construct, pHR-Hutat2:Fc-EGFP, co-expressed the Hutat2:Fc fusion protein under a CMV promoter and the enhanced green fluorescent protein (EGFP) via the internal ribosome entry site (IRES) element. Another transfer plasmid containing an expression cassette for anti-Epstein-Barr virus latent membrane protein $1 \mathrm{scFv}(\mathrm{A} 3 \mathrm{H} 5: \mathrm{Fc})$ was constructed in the same way and used as a control. Lentiviral vectors encoding the Hutat2:Fc (HR-Hutat2) or control (HR-A3H5) genes were generated by transient co-transfection in $293 \mathrm{~T}$ cells with pCMV- $\triangle R 8.2$ and pCMV-VSV-G. Vector production and concentration were performed as described previously [40-42]; $293 \mathrm{~T}$ cells were used for vector titration [25]. High-titer lentiviral vector stocks (3.3 to $4.8 \times 10^{8} \mathrm{U} / \mathrm{mL}$ ) were prepared by sucrose-cushioned ultracentrifugation at 25,000 rpm for 2 hours [40].

\section{Cell lines and culture}

Human embryonic kidney 293 T cells (GenHunter Co., Nashville, TN, USA) were maintained in Dulbecco's Modified Eagle's Medium (Corning Life Sciences, Manassas, VA, USA) supplemented with $1.0 \mathrm{~g} / \mathrm{L}$ glucose, $4 \mathrm{mM} \mathrm{L-}$ glutamine (Sigma-Aldrich, St. Louis, MO, USA), $1.0 \mathrm{mM}$ sodium pyruvate (Corning Life Sciences), $100 \mathrm{IU} / \mathrm{mL}$ penicillin (Sigma-Aldrich), $0.1 \mathrm{mg} / \mathrm{mL}$ streptomycin (SigmaAldrich), $10 \mathrm{mM}$ HEPES (HyClone, South Logan, UT, USA), and 10\% fetal bovine serum (FBS) (HyClone). The human neuroblastoma cell line HTB-11 (ATCC, Manassas, VA, USA), was cultured in Minimum Essential Medium (Eagle) (Corning Life Sciences) supplemented with $2 \mathrm{mM}$ L-glutamine, $1.0 \mathrm{mM}$ sodium pyruvate, $100 \mathrm{IU} / \mathrm{mL}$ penicillin, $0.1 \mathrm{mg} / \mathrm{mL}$ streptomycin, and 10\% FBS. Culture media was replaced every 2 to 3 days and cells were subcultured with EDTA solution containing 0.25\% trypsin (Sigma-Aldrich). The human monocytic cell line U937 (ATCC) was cultured in RPMI 1640 (Sigma-Aldrich) supplemented with $2 \mathrm{mM}$ L-glutamine, $1.0 \mathrm{mM}$ sodium pyruvate, $100 \mathrm{IU} / \mathrm{mL}$ penicillin, $0.1 \mathrm{mg} / \mathrm{mL}$ streptomycin, and $10 \%$ FBS. Cells were maintained at $37^{\circ} \mathrm{C}$ in $5 \% \mathrm{CO}_{2}$.

\section{Isolation and cultivation of hMDM}

Human peripheral blood was anonymously collected from three blood donors (serum negative for HIV-1, hepatitis B, and hepatitis C) with specific approval of the University of Hawaii's Institutional Review Board (UH IRB). Signed consent forms were received from blood donors and the procedures for blood collection and usage were reviewed and approved by the UH IRB. Peripheral blood mononuclear cells were isolated using Ficoll-Paque ${ }^{\mathrm{Tx}}$ Plus (GE Healthcare Biosciences, Piscataway, NJ, USA) and plated at a density of $3.5 \times 10^{6}$ per well in RPMI 1640 medium supplemented with $10 \%$ defined FBS (HyClone), 1\% sodium pyruvate, $100 \mathrm{IU} / \mathrm{mL}$ penicillin, $0.1 \mathrm{mg} / \mathrm{mL}$ streptomycin, and $1,000 \mathrm{U} / \mathrm{mL}$ human macrophage colony stimulating factor (M-CSF; obtained from 5/9 m $\alpha 3-18$ cell conditioned medium, ATCC\#CRL-10154) using 12-well plates, and incubated at $37^{\circ} \mathrm{C}$ in $5 \% \mathrm{CO}_{2}$. Three days later, nonadherent cells were removed and fresh medium was replaced. A half volume of the culture medium was replaced every 3 days. The purity of hMDM culture in vitro was evaluated by staining with a human CD14 monoclonal antibody conjugated with R-phycoerythrin (Caltag Laboratories, CA, USA) as described previously [25].

\section{Primary neuron culture}

Primary mouse neurons were isolated from cortices of early postnatal (P0) Balb/c mice as described previously [43], except that neurons were plated and maintained

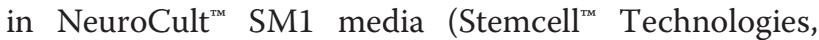
Vancouver, Canada). In brief, pups were decapitated and the brain was collected, washed, and placed into the 
dissection media. Meninges and non-cortical forebrain tissues were removed with fine-point forceps. The cortex was collected and separated into a single-cell suspension by incubating in $20 \mathrm{U} / \mathrm{mL}$ papain solution (Sigma-Aldrich) for 10 minutes, followed by the addition of $100 \mathrm{U}$ DNase I (Sigma-Aldrich) and incubation for 5 more minutes, gentle trituration with a fire-polished glass Pasteur pipette, and filtration through a $0.45-\mu \mathrm{m}$ cell strainer. Cells were then resuspended in NeuroCult ${ }^{\mathrm{TM}} \mathrm{SM} 1$ plating medium and $1 \times 10^{5}$ cells were plated into wells of a 24 -well plate coated with poly-D-lysine (molecular weight, 30 to $70 \mathrm{~K}$; Sigma-Aldrich). A half volume of the culture medium was replaced with fresh NeuroCult ${ }^{\mathrm{TM}}$ SM1 maintenance medium every 3 days. Neurons were maintained at $37^{\circ} \mathrm{C}$ in $5 \%$ $\mathrm{CO}_{2}$ for 6 days before treatments.

\section{Transduction of human cell lines and primary hMDM}

HTB-11 cells were transduced with lentiviral vectors and the transduction efficiency was evaluated following methods described previously [25]. Briefly, HTB-11 cells were sub-cultured at a density of $5 \times 10^{5}$ in a T25 tissue culture flask 24 hours before transduction. For transduction, cell culture medium was removed and cells were washed twice with Dulbecco's Phosphate-Buffered Saline (DPBS) (Corning Life Sciences) followed by addition of $0.5 \mathrm{~mL}$ vector stock (multiplicity of infection, $\mathrm{MOI}=10$ ) containing $8 \mu \mathrm{g} / \mathrm{mL}$ polybrene (Sigma-Aldrich), and incubated at $37^{\circ} \mathrm{C}$ in $5 \% \mathrm{CO}_{2}$ for 2 hours. The vector suspension was removed and fresh growth medium was added. The medium was replaced 24 hours later and transduction efficiency was evaluated on day 3 posttransduction. The percentage of $\mathrm{GFP}^{+}$cells was determined by calculating the number of $\mathrm{GFP}^{+}$cells and total cells from randomly selected microscopic fields using an epi-fluorescence microscope (Nikon Eclipse TE2000-U). All experiments were performed in triplicate and a total of 5 random microscopic fields, each containing at least 100 cells, were counted for each test.

U937 cells were transduced using a spin-infection method. Approximately $1 \times 10^{5}$ cells were resuspended in $100 \mu \mathrm{L}$ of vector suspension $(\mathrm{MOI}=100)$ in the presence of $8 \mu \mathrm{g} / \mathrm{mL}$ polybrene (Sigma-Aldrich) and plated into a 48-well plate. The plate was sealed and spun at $1,500 \times g$ for 90 minutes at $32^{\circ} \mathrm{C}$. Cells were washed with fresh medium and plated into a 12 -well plate and cultured at $37^{\circ} \mathrm{C}$ in $5 \% \mathrm{CO}_{2}$. A second-round transduction was performed the next day. The transduction efficiency was evaluated on day 8 post-transduction as described above.

hMDMs cultured in 12-well plates were infected with HR-Hutat 2 vectors at the MOI of 10 or 50 in the presence of $8 \mu \mathrm{g} / \mathrm{mL}$ polybrene for 1.5 hours on days 7 and 8 in vitro (DIV 7 and DIV 8), respectively. The transduction efficiency was evaluated on day 8 post-transduction
(DIV 16). All experiments were performed in triplicate. A total of five random microscopic fields were counted for each test.

\section{Western blotting}

For western blot assay, cells were washed with DPBS three times, cultured in the serum-free medium, and harvested 2 days later. Cells were lysed with RIPA lysis buffer containing protease inhibitor cocktail (G-Biosiences, St. Louis, MO, USA). The equal volume of serum-free supernatants or the equal amount of total proteins in lysates from transduced or non-transduced cells, including HTB-11, U937, and hMDM cells, were mixed with $5 \times$ sodium dodecyl sulfate (SDS) sample buffer and loaded on $4 \%$ stacking/ $7.5 \%$ separating SDS-polyacrylamide gels (GibcoBRL, Grand Island, NY, USA). Following electrophoresis at $100 \mathrm{~V}$ for 1.5 hours, separated proteins were transferred onto a nitrocellulose membrane (NCM; GE Hybond ECL, Pittsburgh, PA, USA). The NMCs were saturated with $1 \%$ bovine serum albumin (BSA; Sigma-Aldrich) in Trisbuffered saline containing 0.05\% Tween 20 (TBST; SigmaAldrich) for 1 hour at room temperature (RT), followed by incubation with rabbit-anti-human $\operatorname{IgG}_{(\mathrm{H}+\mathrm{L})}(1: 1,000$ dilution) (Rockland, Gilbertsville, PA, USA) for 1 hour at RT. Following extensive washing with TBST, the NCM was incubated with horseradish peroxidase (HRP)-conjugated goat-anti-rabbit IgG at a dilution of 1:3,000 (Rockland) at RT for 1 hour, and then washed three more times with TBST prior to the exposure to a metal enhanced 3,3-diaminobenzidine tetrahydrochloride (DAB) substrate (PIERCE, Rockford, IL, USA) for identification of protein bands. Equal lane loading was assessed using a rabbit anti- $\beta$-actin antibody at a dilution of $1: 1,000$ (Rockland).

\section{Enzyme-linked immunosorbent assay (ELISA)}

Human IgG ELISA was used to quantify the secreted Hutat2:Fc in the culture mediums from transduced HTB11, U937, and hMDM. A 96-well plate was coated with a goat-anti-human IgG Fc capture antibody (Rockland) overnight at $4^{\circ} \mathrm{C}$. The plate was then washed three times with TBST and blocked with TBS containing 1\% BSA (Sigma-Aldrich) for $30 \mathrm{~min}$ at RT on an orbital shaker. After washing three times with TBST, the plate was incubated with diluted Hutat2:Fc containing supernatant samples for 1 hour and then incubated with a goat antihuman IgG Fc biotin-conjugated detection antibody (Rockland) for 1 hour. The plate was then washed and finally incubated with streptavidin-HRP (Rockland) for $30 \mathrm{~min}$ at RT. The presence of Hutat2:Fc protein was detected with tetramethylbenzidine (eBioscience, San Diego, CA, USA). The enzymatic reaction stopped by adding $50 \mu \mathrm{L}$ of $1 \mathrm{M}$ sulfuric acid. The optical density values were read at $450 \mathrm{~nm}$ with $570 \mathrm{~nm}$ as the reference wavelength 
using a microplate reader (Beckman Coulter AD340, Fullerton, CA, USA), and compared with a standard curve of human IgG protein (Sigma-Aldrich, cat\# I2511). Finally, the IgG concentration $\left(\mathrm{C}_{\mathrm{IgG}}\right)$ was transformed to Hutat2: Fc concentration $\left(\mathrm{C}_{\mathrm{Hutat} 2 \mathrm{Fc}}\right)$ in according to the molecular weight $(\mathrm{MW})$ ratio of Hutat2:Fc to IgG $\left(\mathrm{C}_{\text {Hutat2:Fc }}=\mathrm{C}_{\mathrm{IgG}} \times\right.$ $\left.\mathrm{MW}_{\text {Hutat2:Fc }} / \mathrm{MW}_{\mathrm{IgG}}\right)$.

Endogenous IL1 $\beta$, IL8, IL10, and TNF- $\alpha$ levels in the supernatants of hMDM and transduced hMDM were quantified with commercial ELISA kits (human IL1 $\beta$, IL10, and TNF- $\alpha$ ELISA Ready-SET-Go! kit, eBioscience; human IL8 ELISA MAX ${ }^{\mathrm{Tm}}$ kit, BioLegend, San Diego, CA, USA) following the manufacturers' instructions.

\section{Dot-immunobinding assay (DIBA)}

NCM strips were equilibrated in TBS and then air-dried; $200 \mathrm{ng}$ of HIV-1 Tat ${ }_{86}(100 \mu \mathrm{g} / \mathrm{mL})$ (NIH AIDS Reagents Program, Cat\#2222) or Tat dilution buffer were spotted onto the NCM directly and allowed to air-dry for 30 min. After being blocked with 1\% BSA in TBST, the loaded membranes were incubated with conditioned mediums collected from HR-Hutat2 transduced HTB-11, U937, and hMDM, or from HR-A3H5 transduced HTB11 at $4^{\circ} \mathrm{C}$ overnight. Rabbit-anti-human $\operatorname{IgG}_{(\mathrm{H}+\mathrm{L})}(1: 1,000$ dilution) (Rockland) and goat anti-rabbit IgG HRPconjugated (1:3,000 dilution) (Rockland) were used before the exposure to a metal enhanced DAB substrate (PIERCE). Specific binding was visualized by the color deposition on the NCM. The Tat-loaded membrane incubated with rabbit anti-Tat serum (1:1,000 dilution) (NIH AIDS Reagents Program, Cat\#705) followed by the incubation with HRP-conjugated goat anti-rabbit IgG (1:3,000 dilution) served as a positive control.

\section{Real-time PCR}

Total mRNA was extracted from cell samples using High Pure RNA Isolation Kit (Roche, Germany) following the manufacturer's instructions. Total RNA concentration was estimated from absorbance at $260 \mathrm{~nm}$ (A260; Beckman Coulter DU 800) and RNA quality was verified by electrophoresis on ethidium bromide-stained $1.5 \%$ agarose gels and by A260/A280 ratios $>1.8$.

Primers were designed with Primer-BLAST online (http://www.ncbi.nlm.nih.gov/tools/primer-blast/index.cgi? LINK_LOC=BlastHome) and/or express Designer ${ }^{\mathrm{rm}}$ module of express Profiler ${ }^{\mathrm{rm}}$ software (Beckman Coulter), and synthesized from Integrated DNA Technologies (Coralville, IA, USA). Specific primer pairs were used for the expression studies as follows: Hutat2: 5'-ACATCTGTGGTTC TTCCTTCTCCT-3' $/ 5^{\prime}$-TCACTCCATATCACTCCCAG CCACTC-3'; EGFP: 5' -GGTGAGCAAGGGCGAGGAG3'/5'-GCCGGTGGTGCAGATGAACT-3'; ACTB: 5'-AG GTGACACTATAGAATAGGCATCCTCACCCTGAAG TA-3'/5'-GTACGACTCACTATAGGGACAGAGGCGT
ACAGGGATAGC-3'. For the gene expression profiling analysis between transduced and non-transduced hMDM, in total, 15 primer pairs targeting pro-inflammatory cytokines genes, apoptosis-related genes, tumor-related genes, and cell signal transduction genes were used (Table 1). Three reference genes $A C T B, G K$, and Ezrin were used for these normalizations. Primer specificity was confirmed by capillary gel electrophoresis using GenomeLab ${ }^{\text {tax }}$ GeXp gene analysis system (Beckman Coulter) and melt curve analysis. When capillary gel electrophoresis was performed, a universal sequence (Forward: 5'-AGGTGAC ACTATAGAATA-3'; Reverse: 5'-GTACGACTCACTAT AGGGA-3') was added to the $5^{\prime}$-end of each forward or reverse primer following the manufacturer's instructions. cDNA was synthesized from $1 \mu \mathrm{g}$ DNase-treated total RNA by using a Transcriptor First Strand cDNA Synthesis Kit (Roche, Germany) according to the manufacturer's instructions.

Real-time PCR was performed with i-Cycler iQ5 Realtime Detection System (Bio-Rad Laboratories Inc., Hercules, CA, USA). Each sample was amplified in triplicate using 96-well optical plates (Bio-Rad Laboratories Inc.) in a $20 \mu \mathrm{L}$ reaction volume using $2 \mu \mathrm{L}$ cDNA (10 ng/ $\mu \mathrm{L}), 10 \mu \mathrm{L}$ FastStart Universal SYBR Green Master (Roche), and $200 \mathrm{nM}$ of the appropriate forward and reverse primers. Real-time cycling conditions were as follows: initial denaturation at $95^{\circ} \mathrm{C}$ for $10 \mathrm{~min}$, followed by 40 cycles of denaturation at $95^{\circ} \mathrm{C}$ for $15 \mathrm{sec}$ and annealing at $60^{\circ} \mathrm{C}$ for $60 \mathrm{sec}$, and, finally, melt curve analysis. Template-minus and reverse transcriptase-minus negative controls were run for each plate and each sample, respectively. Fold change of gene expression was determined using the arithmetic comparative method $\left(2^{-\Delta \Delta C t}\right)$. Three batches of transduced or mock control cells were tested in all experiments. All real-time PCR tests were done in triplicates.

\section{Fluorescent immunocytochemistry}

Cells were fixed with $4 \%$ paraformaldehyde for $10 \mathrm{~min}$ and blocking was performed by incubating for $15 \mathrm{~min}$ with 1\% BSA in PBS containing 0.1\% Triton X-100 (Sigma-Aldrich). For human IgG Fc staining, cells were incubated with primary antibody, rabbit anti-human IgG Fc at a dilution of 1:100, and a secondary antibody goatanti-rabbit IgG conjugated with tetraethyl rhodamine isothiocyanate (TRITC) at a dilution of 1:200 (Rockland Immunochemical). For mouse neuron staining, cells were incubated with a rabbit anti-microtubule-associated protein 2 (MAP2) antibody (1:200 dilution) (Millipore, Billerica, MA, USA), and then incubated with a goat anti-rabbit IgG TRITC conjugated antibody (1:200 dilution) (Jackson ImmunoResearch Laboratories, West Grove, PA, USA). For HIV-1 p24 staining, after fixing and blocking, hMDM were incubated with an anti-HIV-1 p24 monoclonal 


\begin{tabular}{|c|c|c|c|c|c|}
\hline & $\begin{array}{l}\text { Gene } \\
\text { name }\end{array}$ & $\begin{array}{l}\text { Accession number } \\
\text { [GenBank] }\end{array}$ & Description & Forward sequence $\left(5^{\prime} \rightarrow 3^{\prime}\right)$ & Reverse sequence $\left(5^{\prime} \rightarrow 3^{\prime}\right)$ \\
\hline 1 & IL18 & NM_001562 & Interleukin 18 & TCAGACCTTCCAGATCGCTT & TGCCACAAAGTTGATGCAAT \\
\hline 2 & FAS & NM_000043 & Fas cell surface death receptor & ACTGTGACCCTTGCACCAAA & GCCACCCCAAGTTAGATCTGG \\
\hline 3 & $E Z R^{*}$ & X51521 & Ezrin & GCCTAGAGGCTGACCGTATG & TGTGTATTCTGCAAGCTCCG \\
\hline 4 & P53 & NM_000546 & Tumor protein p53 & CTTCGAGATGTTCCGAGAGC & TTATGGCGGGAGGTAGACTG \\
\hline 5 & $T L R 1$ & NM_003263 & Toll-like receptor 1 & GACTGCCAAATGGAACAGACA & AGGGCCTGGTACCCCTATTA \\
\hline 6 & $G K^{*}$ & NM_203391 & Glycerol kinase & CTACAATGCTGTGGTGTGGC & TCAAGGAGCCAACGAAGTTT \\
\hline 7 & 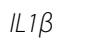 & NM_000576 & Interleukin $1 \beta$ & CCTCCAGGGACAGGATATGGA & CCAGCTGTAGAGTGGGCTTA \\
\hline 8 & 128 & NM_000584 & Interleukin 8; neutrophil chemotactic factor & CACCGGAAGGAACCATCTCA & TTGGGGTGGAAAGGTTTGGA \\
\hline 9 & IDO1 & NM_002164 & Indoleamine 2,3-dioxygenase 1 & TATTTGTCTGGCTGGAAAGGC & GGAGGAACTGAGCAGCATGTC \\
\hline 10 & NFKB2 & NM_001077494 & $\begin{array}{l}\text { Nuclear factor of kappa light polypeptide } \\
\text { gene enhancer in B-cells } 2 \text { (p49/p100) }\end{array}$ & AGCAAGAGGCCAAAGAACTG & TGCTGTCTTGTCCATTCGAG \\
\hline 11 & IFNGR2 & NM_005534 & Interferon gamma receptor 2 & CTGATCTCCGTGGGAACATT & TCCTITGGTGAGCTGTCCTT \\
\hline 12 & STAT1 & NM_007315 & Signal transducer and activator of transcription 1 & CTGAGGAGTTTGACGAGGTGT & CTATCAACAGGTTGCAGCGAA \\
\hline 13 & CCR5 & NM_000579 & Chemokine ( $\mathrm{C}-\mathrm{C}$ motif) receptor 5 & GGGATAGCACTGAGCAAAGC & TCTGAAATACGGAGGCTGGT \\
\hline 14 & $C C L 2$ & NM_002982 & $\begin{array}{l}\text { Chemokine (C-C motif) ligand 2; monocyte } \\
\text { chemotactic protein-1 (MCP-1) }\end{array}$ & GCCTCCAGCATGAAAGTCTC & AGATCTCCTTGGCCACAATG \\
\hline 15 & CASP3 & NM_004346 & Caspase3, apoptosis-related cysteine peptidase & AGCGAATCAATGGACTCTGG & AACATCACGCATCAATTCCA \\
\hline 16 & ACTB* & NM_001101 & Beta-actin & GGCATCCTCACCCTGAAGTA & CAGAGGCGTACAGGGATAGC \\
\hline 17 & IL10 & NM_000572 & Interleukin 10 & CGGCGCTGTCATCGATTTCT & GTTCTCAAGGGGCTGGGTC \\
\hline 18 & $T N F-a$ & NM_000594 & Tumor necrosis factor-a & CAGAGGGAAGAGTTCCCCAG & CCTTGGTCTGGTAGGAGACG \\
\hline
\end{tabular}

*Reference gene.

antibody (1:500 dilution) (NIH AIDS Reagents Program, Cat\#530) followed by incubation with goat anti-mouse IgG conjugated to biotin (1:200 dilution) (Vector labs, Burlingame, CA, USA), and with streptavidin-TRITC (1:200 dilution) (Jackson ImmunoResearch Laboratories) subsequently. For CD14 staining, cells were not fixed and permeabilized. After three washings with PBS, hMDM were incubated with a human CD14 monoclonal antibody conjugated with R-phycoerythrin (1:100 dilution) (Caltag Laboratories, CA, USA). To stain nuclei, cells were incubated with 4',6-diamidino-2-phenylindole (DAPI) (SigmaAldrich) for $5 \mathrm{~min}$. All the incubations were followed by extensive washing with PBS. Negative controls consisted of pre-incubation with 1\% BSA in PBS containing 0.1\% Triton X-100 and omission of the primary antibody followed by corresponding secondary antibody. To detect apoptosis in neurons, a terminal dexoynucleotidyl transferase-mediated dUTP nick end labeling (TUNEL) assay using MEBSTAIN Apoptosis TUNEL Kit II (MBL, Woburn, MA, USA) was performed according to the manufacturer's instructions. Immunofluorescent images were obtained with an inverted epi-microscope (Nikon Eclipse TE2000-U) using a numerical aperture lens (0.30 or 0.45 ) and a digital camera attachment. The pictures were overlaid using ImageJ software (Version 1.48, National Institutes of Health, USA).

\section{MTT assay}

HTB-11 cells at the exponential growth phase were seeded into 96 -well plates at $1 \times 10^{4}$ cells/well in $100 \mu \mathrm{L}$ and cultured for 48 hours. Twenty milliliters of MTT solution $(5 \mathrm{mg} / \mathrm{mL}$ ) (Sigma-Aldrich) was added to the $100 \mu \mathrm{L}$ of medium in each well, and the plate incubated at $37^{\circ} \mathrm{C}$ for 4 hours. The solution was removed, followed by the addition of $100 \mu \mathrm{L} /$ well of dimethylsulfoxide (Amresco, Solon, OH, USA) to solubilize the purple formazan crystals produced. Absorbance in each well was measured at $570 \mathrm{~nm}$ using a 96-well plate reader (Beckman Coulter AD340). To evaluate the neuroprotective effects of the Hutat2:Fc, HTB-11 cells were treated with HIV-1 $\mathrm{Tat}_{86}(500 \mathrm{nM}), \mathrm{Tat}_{86}$, plus the conditioned medium from HR-Hutat2 transduced HTB-11, U937, or hMDM at a dilution of 1:5. Treatment with Tat 86 plus anti-Tat antibody was used as a positive control, while Tat ${ }_{86}$ plus the conditioned mediums from the HR-A3H5 transduced HTB-11 was used as a negative control. Seventy-two hours later, an MTT assay was performed as noted above. In some experiments, the vector HR-Hutat2 transduced HTB-11 cells were treated with HIV-1 Tat $_{8} 6(500 \mathrm{nM})$ for 72 hours and an MTT assay was performed. The vector HR-A3H5transduced HTB-11 treated with HIV-1 Tat t6 $_{86}$ was used as a negative control. All experiments were performed in quadruplicate. 


\section{Primary neuron protection assay}

For this experiment, all the tested conditioned mediums were FBS-free to avoid possible stimulation of astrocyte growth, and the conditioned mediums from the transduced hMDM on day 9 post-transduction were tested as representative samples, since the mediums contained the highest level of Hutat2:Fc as compared to the supernatants harvested on the other days. Mouse primary neurons cultured in 24-well plates were treated with HIV-1 Tat $_{86}$ (500 nM) alone, or Tat adding with the conditioned mediums from HR-Hutat2 transduced hMDM or HTB-11 (1:5 dilution) on DIV 6 for 3 days. Treatments with Tat $_{86}$ plus anti-Tat monoclonal antibody $(\mathrm{NIH}$ AIDS Reagents Program, Cat\#7377) was used as a positive control while $\mathrm{Tat}_{86}$ plus the conditioned mediums from the HR-A3H5 transduced HTB-11 was used as a negative control, respectively. Three days later (DIV 9), cells were fixed with $4 \%$ paraformaldehyde and counterstained with anti-MAP2 (neuron) followed by TUNEL (apoptosis) labeling, and DAPI (nuclei) staining as described above. Fields were chosen randomly, and at least five images from five random fields were acquired with an epi-fluorescence microscope (Nikon Eclipse TE2000-U) from each of three independent experiments. In normal neuron culture, there were some TUNEL-positive cells. It was reported that these represented non-neuronal dividing cells that were undergoing cell death and apoptotic neurons from the preparation procedure [43]. Note that around these structures intact cell bodies were not observed when the images were overlaid together. Therefore, in this neuron survival evaluation, only the neurons which had intact cell bodies (red) and nuclei (blue), yet were resistant to TUNEL labeling (green), were calculated as survivals. The number of surviving neurons and total neuron numbers were counted manually. The ratio of living neurons in normal neuron culture was arbitrarily defined as $100 \%$ neuron survival rate. The relative neuron survival rate (\%) was expressed as a percentage relative to the untreated control neurons. Each value is the mean obtained from five random microscopic fields of three independent experiments using a $20 \times$ objective.

\section{HIV-1 challenge}

HIV $-1_{\text {Ba-L }}$ strain (R5) was obtained from the NIH AIDS Reagent Program (Cat\#510). Human MDM were isolated and transduced with HR-Hutat2 vectors on DIV 7 and DIV 8. Six-days later, non-transduced hMDM, transduced hMDM, non-transduced hMDM with antiHIV-1 Tat monoclonal antibody (1:100 dilution), or the conditioned medium from transduced hMDM (1:2 dilution) were incubated with cell-free $\mathrm{HIV}-1_{\mathrm{Ba}-\mathrm{L}}$ (final concentration of p24 $7.8 \mathrm{ng} / \mathrm{mL}$ ) at $37^{\circ} \mathrm{C}$ for 2 hours, respectively. Cells were washed three times and fresh medium was added. Half volumes of the culture supernatants were collected and replaced with fresh medium every 3 days for a total of 24 days. Anti-HIV-1 Tat or the conditioned medium from transduced hMDM were supplemented to the appropriate wells when medium was replaced. Viral replication was gauged for p24 levels in the culture supernatants using a commercial HIV-1 p24 ELISA kit (Beckman Coulter) in accordance with the manufacturer's instructions. The blood from three donors was used in this test and triple independent experiments were performed.

\section{Statistical analysis}

Statistical analyses were performed by running the SPSS Version 16.0 for Windows package. Data were reported in the text as means \pm standard error means (s.e.m). Student's $t$-test and $\chi^{2}$ test were used to determine the statistical significance of independent data, appropriately. One-way analysis of variance (ANOVA) followed by Tukey's multiple comparison post hoc test was used to analyze studies with three or more experimental groups. Comparisons of each group with the control used Dunnett test. The $P$ values were two-tailed and a $P$ value less than 0.05 was considered to be significant.

\section{Results}

Evaluation of the gene transfer efficiency and the stable expression of anti-HIV-1 Tat Hutat2:Fc in human neuronal cell line HTB-11, monocytic cell line U937, and primary hMDM

The efficiency of lentiviral vector-mediated gene transfer was evaluated initially in human neuronal and monocytic cell lines. Human neuroblastoma cell line HTB-11 and monocytic cell line U937 were transduced with lentiviral vectors HR-Hutat2 at a MOI of 10 and 100, respectively. Under the established experimental conditions, transduction efficiencies were calculated to be $98.5 \% \pm$ $0.8 \%$ for HTB-11 cells and $95.4 \% \pm 2.5 \%$ for U937 cells (Figure 1A). Furthermore, the expression of the integrated genes was confirmed by examining transduced HTB-11 for the Fc expression using immunofluorescent staining with an anti-human IgG Fc specific antibody. EGFP proteins were expressed in both the nuclei and cytoplasm, whereas Hutat2:Fc was predominately distributed in the cytoplasm (Figure 1B). HTB-11 cells were also transduced with control vectors HR-A3H5 containing a construct encoding the anti-Epstein-Barr virus latent membrane protein $1 \mathrm{scFv}$ A3H5 fused to Fc. The transduction efficiency was as high as that obtained from HR-Hutat2 transduced HTB-11 cells (data not shown).

Next, we tested whether the vector HR-Hutat2 could successfully transduce non-dividing primary hMDMs. The purity of the cultured hMDMs was proved to be $>98 \%$ by $\mathrm{CD}_{14}{ }^{+}$immunofluorescent staining on DIV 6 (Additional file 2). hMDMs were infected with the 


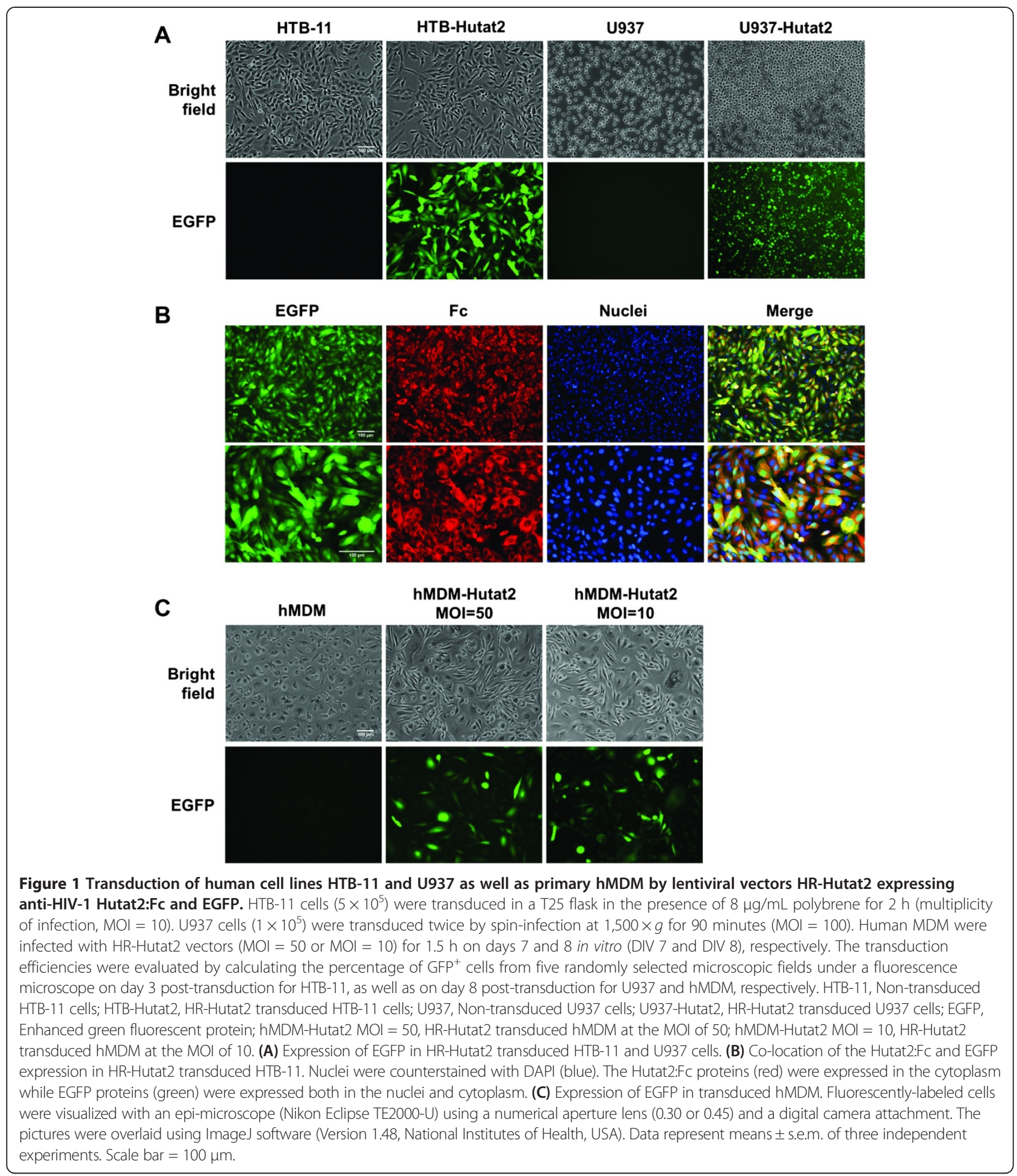

concentrated HR-Hutat2 stock $(\mathrm{MOI}=50)$ or unconcentrated stock $(\mathrm{MOI}=10)$ on DIV 7 and DIV 8. The transduction efficiencies were approximately $53.3 \%$ and $47.6 \%$, respectively (Figure 1C). There were no significant differences in the transduction efficiency between the two MOI groups $(P>0.05)$.
Furthermore, the transcriptional profiling for the integrated Hutat2 and EGFP genes in transduced HTB-11, U937, and hMDM were examined by RT-PCR analysis (Figure 2A) and confirmed by a real-time PCR test. The expression of Hutat2 and EGFP genes in transduced cells was normalized with three reference genes $(A C T B$, 

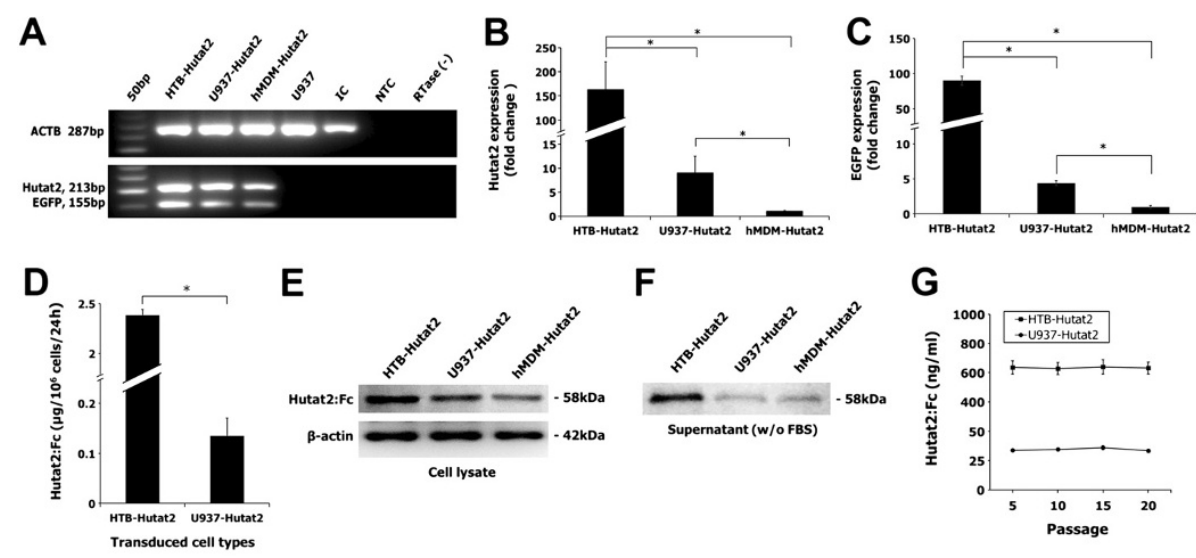

$\mathbf{F}$

$\mathrm{H}$
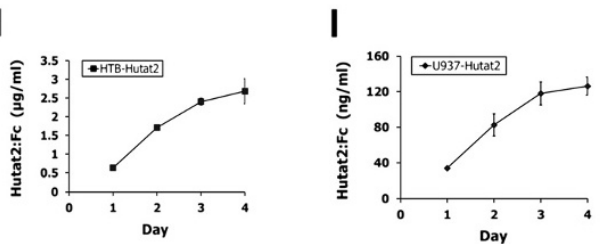

G
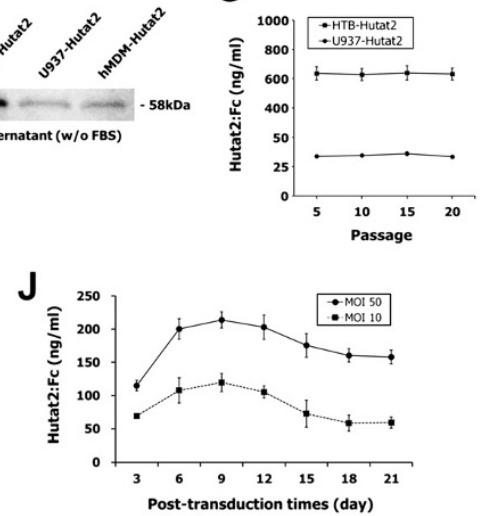

Figure 2 Relative gene expression levels of the Hutat2:FC and EGFP genes in transduced cells and quantification of Hutat2:Fc in conditioned mediums. (A) Detection of Hutat2 and EGFP mRNA in HR-Hutat2 transduced cells by a RT-PCR qualitative analysis. HTB-Hutat2, HR-Hutat2 transduced HTB-11 RNA; U937-Hutat2, HR-Hutat2 transduced U937 RNA; hMDM-Hutat2, HR-Hutat2 transduced hMDM RNA; U937, non-transduced U937 RNA; IC, Internal control RNA from K562 cell line; NTC, No template control; RTase (-), RTase negative control. (B and C) Quantitative real-time PCR analysis of Hutat2 and EGFP gene expression levels in transduced HTB-11 and U937 cells compared with that in transduced hMDM $\left({ }^{*} P<0.01\right)$. (D) Comparison of Hutat2:Fc secretion level between transduced HTB-11 and U937 within 24 hours ( ${ }^{*} P<0.01$ ); $1 \times 10^{6}$ cells were plated into a T-75 flask and the mediums were collected 24 hours later. Hutat2:Fc was quantified by a human IgG ELISA method. (E and F) Detection of Hutat2:Fc proteins in cell lysate and supernatant of transduced cells by Western blotting. (G) Detection of stable secretion of Hutat2:FC in conditioned mediums from HR-Hutat2 transduced HTB-11 (HTB-Hutat2) and U937 cells (U937-Hutat2). Cells were passaged totally 20 times and an ELISA assay was performed every fifth passage. (H and I) The accumulation of Hutat2:Fc in mediums from transduced HTB-11 and U937 cells; $1 \times 10^{6}$ cells were plated into a T-75 flask and the mediums were collected every 24 hours for 4 days. (J) Kinetics of Hutat2:Fc levels in cell culture supernatants of transduced hMDM at different MOI after transduction. The levels of secreted Hutat2:Fc were peak on day 9 post-transduction. The concentrations of Hutat2:Fc were higher at MOI 50 than at MOI 10 in mediums of transduced hMDM at each time point $(P<0.01)$. Results shown represent mean values from three independent experiments. Error bars denote the s.e.m.

GK, and Ezrin) and compared with transduced hMDM. The expression levels of the Hutat 2 gene in transduced HTB-11 and transduced U937 were 162.5- and 9.0-fold higher than that in transduced hMDM, respectively, while the expression level of the Hutat2 gene in transduced HTB-11 was 18.1-fold higher than that in transduced U937 (Figure 2B). In addition, the expression levels of EGFP in transduced HTB-11 and U937 cells were 89.7- and 4.4-fold higher than that determined in transduced hMDM, respectively (Figure $2 \mathrm{C}$ ). The difference in the gene expression between different transduced cells was further confirmed by an ELISA quantification of Hutat2:Fc secreted in the supernatants of transduced HTB-11 and U937 cells. It was shown that the secretion of Hutat2:Fc in the supernatants of transduced HTB-11 was 17.1-fold higher than that in the supernatants of transduced U937 cells $\left(2.39 \pm 0.11 \mu \mathrm{g} / 10^{6}\right.$ cells $/ 24$ h compared with $0.14 \pm 0.04 \mu \mathrm{g} / 10^{6}$ cells $/ 24 \mathrm{~h}$, $P<0.01$ ) (Figure 2D).

The expression and secretion of Hutat2: $\mathrm{Fc}$ in the transduced HTB-11, U937, and hMDM cells were confirmed by Western blotting. To assess the production of Hutat2:Fc extracellularly and intracellularly, cell culture supernatants containing no FBS and cell lysates from the above transduced cells were collected or extracted. Vector-transduced cells expressed Hutat2:Fc both within cells (cell lysate) and in secreting form (culture supernatant) (Figure 2E,F). The molecular weight of Hutat2:Fc fusion protein is approximate $58 \mathrm{kDa}$.

To quantify the stability of Hutat2:Fc expression and secretion, transduced HTB-11 and U937 cells were subcultured in vitro for up to 20 passages. The concentration of Hutat2:Fc in the conditioned medium was assessed using an ELISA method at every fifth passage. Our data showed the levels of Hutat2:Fc in the conditioned mediums were stable over the course of 20 cell passages in HR-Hutat2 transduced cells (Figure 2G). The percentage of $\mathrm{GFP}^{+}$cells in these transduced cell populations was also found to be stable through the course of the 20 passages (data not shown). In addition, the secreted Hutat2:Fc could be accumulated in the conditioned mediums of transduced HTB-11 and U937 
during a 4-day examination (Figure $2 \mathrm{H}, \mathrm{I}$ ). The concentration increased exponentially with time and reached to plateau on day $4(2.68 \pm 0.33 \mu \mathrm{g} / \mathrm{mL}$ for HTB-Hutat2 and $126.16 \pm 10.12 \mathrm{ng} / \mathrm{mL}$ for U937-Hutat2).

The levels of secreted Hutat2:Fc in cell culture supernatants of transduced hMDM were peak on day 9 posttransduction (DIV 17) in both the MOI 50 group $(213.83 \pm 12.03 \mathrm{ng} / \mathrm{mL})$ and MOI 10 group $(119.66 \pm$ $13.64 \mathrm{ng} / \mathrm{mL}$ ), and then gradually fell to $158.06 \pm$ $10.41 \mathrm{ng} / \mathrm{mL}$ and $59.45 \pm 8.36 \mathrm{ng} / \mathrm{ml}$ in these two groups on day 21 (DIV 29), respectively (Figure 2J). The Hutat2: Fc secreted into the cell culture mediums could be detected as early as day 3 post-transduction, expressed much earlier than the expression of EGFP, which became visibly apparent on day 8 post-transduction. These findings as well as the gene expression profiling indicated that the expression of genes co-expressed through an IRES element was weaker than the promoter-proximal gene(s) [44]. Transduced hMDM were maintained in good condition for up to 30 days in vitro.

\section{Specific binding of expressed Hutat2:Fc to HIV-1 Tat}

After confirming the stable expression of Hutat2:Fc, an immunoblot assay was employed to assess the specific binding ability of secreted Hutat2:Fc to HIV-1 Tat. Recombinant HIV-1 Tat ${ }_{86}$ (Clade B) was diluted and blotted onto a NCM with the dilution buffer included as a blank control. The conditioned medium from HR-A3H5 transduced HTB-11 served as a negative control and anti-HIV-1 Tat serum served as a positive control. The conditioned mediums containing anti-HIV-1 Tat Hutat2: Fc from transduced HTB-11 and U937 cells as well as hMDM bound specifically to HIV-1 Tat ${ }_{86}$ while no binding was detected to neither the blank control nor the secreted $\mathrm{A} 3 \mathrm{H} 5: \mathrm{Fc}$ control (Figure 3A). In addition, to confirm that the Hutat2:Fc was able to bind the unaggregated form of Tat, Tat 86 was separated by SDS-PAGE electrophoresis and Western blot assay was performed using the conditioned medium from transduced cells as primary antibodies. In accordance with the DIBA results, Hutat2:Fc from HR-Hutat2 transduced cells could specifically bind to $\mathrm{Tat}_{86}(14 \mathrm{kDa})$, whereas A3H5:Fc from HR-A3H5 transduced HTB-11 could not (Additional file 3). These tests demonstrate that the secreted Hutat2:Fc is able to bind specifically and sufficiently to HIV Tat 86 as a fully-functional HIV-1 Tat antibody in vitro, as designed.

\section{Protection of Hutat2:Fc against HIV-1 Tat-mediated neurotoxicity}

The next important step was to determine whether binding of anti-HIV-1 Tat Hutat2:Fc to HIV-1 Tat ${ }_{86}$ can successfully neutralize the neurotoxic properties of Tat $_{86}$. The ability of Hutat2:Fc to antagonize the toxicity of HIV-1 Tat 86 was assessed by using an MTT assay to determine if the secreted Hutat2:Fc or vector transduction was able to protect HTB-11 cells against the neurotoxic impact of HIV-1 Tat ${ }_{86}$. When exposed to Tat 86 (500 nM), normal HTB-11 cells exhibited a reduced cellular viability $(59.4 \pm 7.8 \%)$. Comparatively, HTB-11 cells
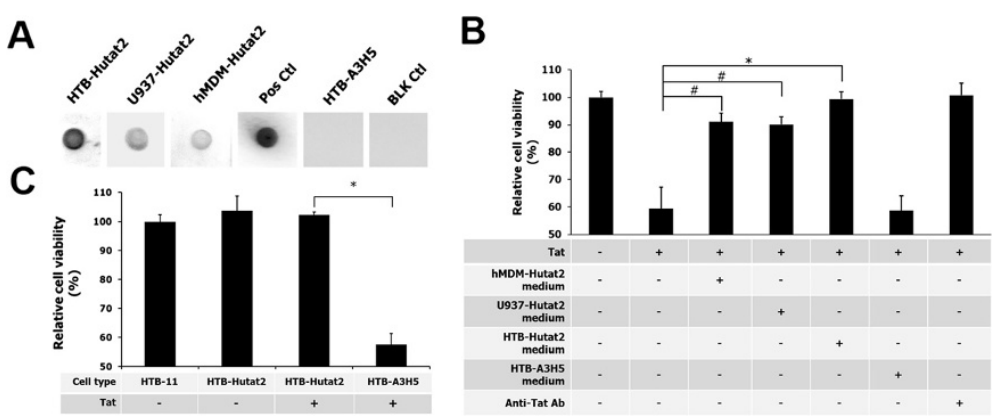

Figure 3 Evaluation of the biological binding function of Hutat2:Fc and protective effects of Hutat2:Fc against HIV-1 Tat ${ }_{86}$-mediated toxicity in HTB-11 cells. (A) Specific binding of Hutat2:Fc to HIV-1 Tat. HIV-1 Tat ${ }_{86}$ (Clade B) loaded nitrocellular membranes (NCM) were incubated with cell culture supernatants collected from HR-Hutat2-transduced HTB-11 (HTB-Hutat2), U937 (U937-Hutat2), or hMDM (hMDM-Hutat2) at $4^{\circ} \mathrm{C}$ overnight followed by incubation with rabbit anti-human $\lg _{(\mathrm{H}+\mathrm{L})}$ and goat anti-rabbit lgG HRP conjugated antibodies. Specific binding was visualized by the color deposition on the NCM. The Tat ${ }_{86}$-loaded membrane incubated with rabbit anti-Tat serum served as a positive control (Pos Ctl) while incubated with cell culture supernatant from HR-A3H5 transduced HTB-11 served as a negative control (HTB-A3H5). The NCM loaded with Tat dilution buffer was used as a blank control (BLK CtI). (B) Functional antagonization of Hutat2:Fc against HIV-1 Tat 86 -induced toxicity in HTB-11 cells by an MTT assay. The $\mathrm{OD}_{570}$ value of untreated HTB-11 cells was arbitrarily defined as $100 \%$ cell viability. The relative cell viability (\%) was expressed as a percentage relative to the untreated control cells. The cell viability was significantly higher for the cells treated with the conditioned mediums from transduced cells releasing Hutat:Fc when compared to the cultures that received Tat 86 (500 nM) alone ${ }^{*} P<0.01$ for HTB-Hutat2 medium; ${ }^{*} P<0.05$ for U937-Hutat2 medium, and hMDM-Hutat2 medium). (C) Protection of HR-Hutat2 transduction against Tat 86 -induced toxicity by an MTT assay. No significant difference of cell viability was detected between normal and vector HR-Hutat2 transduced HTB-11 cells (HTB-Hutat2) $(P>0.05)$. However, the cell viability of HTB-11 transduced with the vector HR-Hutat2 was significantly higher than that of HTB-A3H5 in the presence of HIV-1 Tat $86(500 \mathrm{nM})\left({ }^{*} P<0.01\right)$. All experiments were performed in quadruplicate. Error bars denote the s.e.m. 
exposed to $\mathrm{Tat}_{86}$ in the presence of the conditioned mediums from HR-Hutat2 vector-transduced HTB-11, U937, or hMDM were protected from cellular cytotoxicity (cell viability was $99.4 \pm 2.6 \%, 90.1 \pm 2.8 \%$, and 91.1 $\pm 3.1 \%$, respectively; Figure $3 \mathrm{~B}$ ). The slightly lower level of cyto-protective effects of the conditioned medium from the transduced hMDM compared to that from the transduced HTB-11 was due to the lower concentration of Hutat2:Fc in the conditioned medium. Furthermore, when exposed to Tat 86 , HR-Hutat2 transduced HTB-11 cells also showed a dramatically increase in cell viability of $102.1 \pm 1.1 \%$ in comparison to HR-A3H5-transduced HTB-11 cells, which only had a viability of $57.5 \pm 3.8 \%$. The viability of HR-Hutat2- transduced HTB-11, either exposed to HIV-1 Tat or not, was comparable to the normal HTB-11 control (Figure 3C). These data indicated that both HR-Hutat2-transduced HTB-11 itself and the Hutat2:Fc proteins in the supernatants significantly mediated the cytoprotective effects. Taken together, these data reflect the ability of Hutat2:Fc to neutralize the biological activity of Tat ${ }_{86}$.

In addition, these protective effects of Hutat2:Fc in the conditioned mediums were further evaluated using primary cultures of mouse neurons. Early postnatal (P0) $\mathrm{Balb} / \mathrm{c}$ mouse neurons from cortex were isolated and cultured for 6 DIVs. The purity of the cultures were $>95 \%$ neurons proved by MAP2 and glial fibrillary acidic protein immunocytochemistry staining (data not shown). The representative images of normal neurons and neurons treated with $\mathrm{Tat}_{86}$ or Tat ${ }_{86}$ plus Hutat2:Fc containing mediums from the transduced hMDM are shown in Figure 4A. Tat-treated mouse neurons showed increased numbers of cell apoptosis (Figure 4A TUNEL panel), loss of dendritic arbor, as well as a shorter dendrite length (Figure 4A; MAP2 panel). The relative rate of neuron survival was similar among normal neurons, neurons treated with Tat $_{86}$ plus conditioned medium from HTB-Hutat2 $(93.0 \pm 4.5 \%)$, and neurons treated with Tat ${ }_{86}$ plus anti-Tat antibody $(97.0 \pm 7.2 \%)$. Compared with Tat exposure alone, the relative rate of neuron survival was increased by $10 \%$, from $69.3 \pm 8.9 \%$ to $79.4 \pm 7.9 \%$ in the presence of conditioned medium from HR-Hutat2-transduced hMDM $(P<0.05)$. However, the neuron survival rates were not significantly changed when adding HTB-A3H5 medium $(66.6 \pm 9.6 \%$ versus $69.3 \pm 8.9 \%, P>0.05$; Figure $4 \mathrm{~B})$. These results indicate that Hutat2:Fc released from transduced hMDM and HTB-11 could neutralize HIV-1 Tat ${ }_{86}$-induced neurotoxicity as an anti-Tat antibody in vitro, whereas A3H5:Fc released from HTB-A3H5 control does not have that biological effect. In comparison, the protective level of Hutat2:Fc from the conditioned medium of transduced hMDM was lower than that obtained from the use of transduced HTB-11 medium and the commercial anti-Tat antibody.

\section{Transduced hMDM culture and culture medium resist challenge with infectious HIV-1}

To determine if HR-Hutat2-mediated transduction of hMDM could inhibit virus infection, both transduced and normal hMDM control were exposed to full-length infectious HIV-1 $1_{\mathrm{Ba}-\mathrm{L}}$.

hMDM was transduced with HR-Hutat2 on DIV 7 and DIV 8 and cultured for 6 days, then normal hMDM, HRHutat2-transduced hMDM, and hMDM supplemented with anti-HIV-1 Tat or with the conditioned medium from HR-Hutat2-transduced hMDM were infected with HIV$1_{\mathrm{Ba}-\mathrm{L}}$, respectively. The level of HIV-1 p24 production in these cultures was quantified by an ELISA assay (Figure 5A). HIV-1 $1_{\mathrm{Ba}-\mathrm{L}}$ replication (p24 level) was detected in the control hMDM shortly after virus inoculation (day 3 ) and gradually increased with post-infection time, reaching the peak level by day 18 post-infection. The level of viral production dramatically suppressed (by 9- to 16-fold) in transduced hMDM-Hutat2 and normal hMDM supplemented with hMDM-Hutat2-conditioned medium or with anti-HIV-1 Tat antibody as compared to normal hMDM cultures (Figure 5A). These results suggest that the lentiviral vector-mediated Hutat2:Fc gene transfer conferred a significant degree of protection against wild-type HIV-1 infection in primary hMDM $(P<0.01)$. In addition, the secreted Hutat2:Fc from transduced hMDM can suppress HIV-1 $1_{\text {Ba-L }}$ propagation as an anti-HIV-1 Tat antibody. In agreement with this, an HIV-1-induced cytopathic effect in non-transduced hMDM was evident by the presence of abnormally large cells, multinucleated cells, and debris resulting from late stages of cell death. As a comparison, only very modest levels of HIV-1-induced cytopathic effects were observed in the transduced cultures or nontransduced culture supplemented with Hutat2:Fc conditioned medium (Figure 5B). Furthermore, although almost all of hMDM were infected by HIV-1 $1_{\text {Ba-L }}$ after a 24-day culture period, the fluorescent signals of p24 staining in transduced hMDM or in normal hMDM treated with hMDM-Hutat2 conditioned medium were much weaker as compared to hMDM control (Figure 5B; p24 panel). These findings illustrate that although Hutat2:Fc is unable to completely block the cells from infection by HIV, lentiviral vector HR-Hutat2-transduced hMDM (intracellular Hutat2:Fc) and the Hutat2:Fc secreted from vectortransduced hMDM (extracellular Hutat2:Fc) are able to suppress HIV-1 replication and the spread of viral infection in macrophages.

\section{Potential adverse impacts}

A vital component of gene therapy is to ensure that neither the method of gene delivery nor the subsequent gene expression causes any adverse effect on the target cells or tissues. Several experimental tests were conducted to evaluate the lentiviral vector-mediated transduction of 


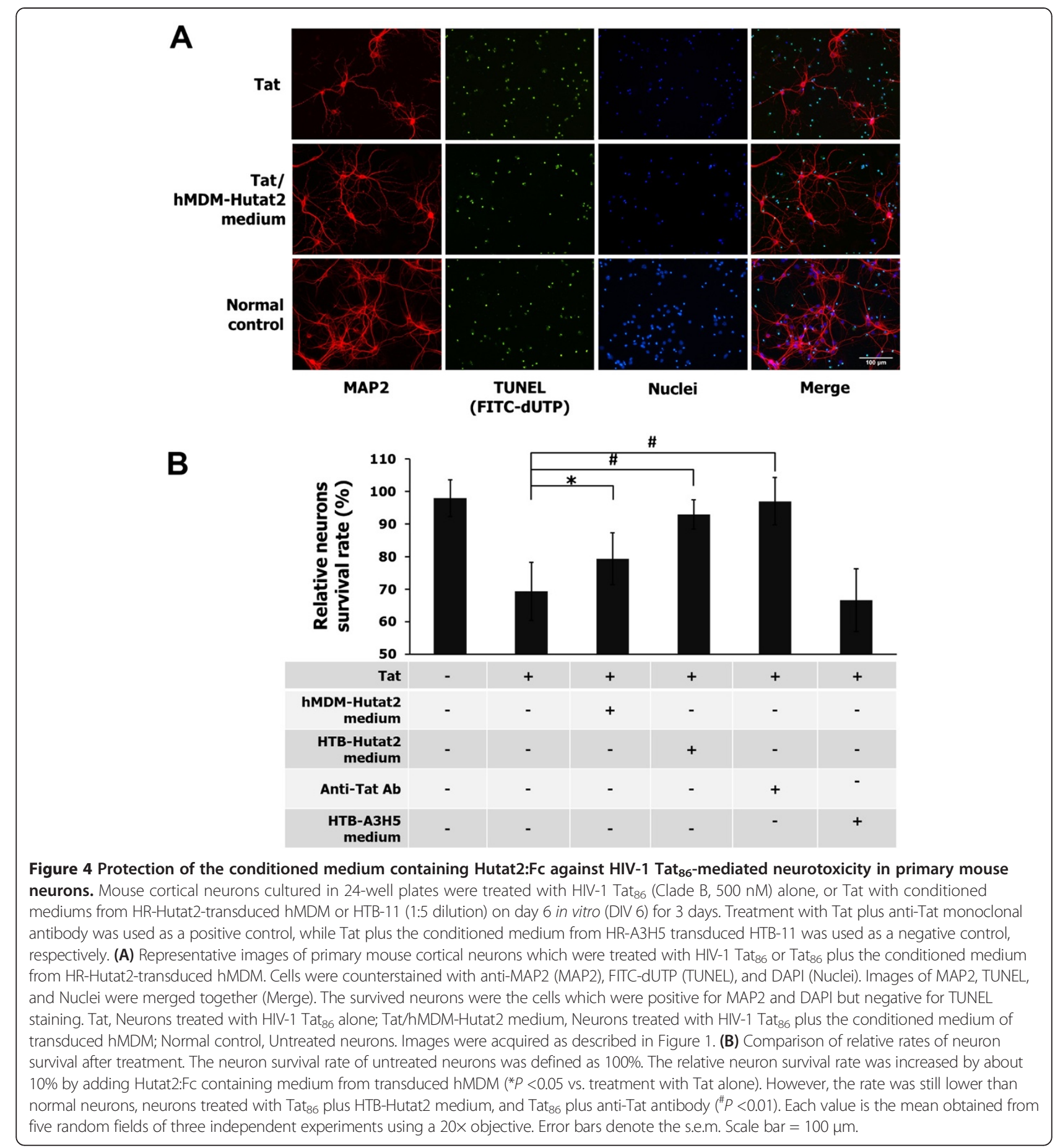

cells for potential changes of cellular function including cell morphology, proliferation, and cellular activation in the transcriptional profiling of macrophage-related functional and regulatory genes, and in the releasing of proinflammatory cytokines in transduced hMDM.

First, the comparison of transduced and non-transduced cells shows no apparent alternation in cell morphology following the transduction with HR-Hutat2 in both cell lines and primary hMDM (Figure 1A,C). Transduced cell lines were monitored for more than 20 passages, and no change in growth kinetics was observed during that time. In addition, there were no significant differences in cellular viability between normal HTB-11 and HR-Hutat2-transduced HTB-11, as determined by an MTT assay (Figure 3C).

Second, a qRT-PCR assay was employed to comparatively evaluate the expression of 15 human macrophage- 

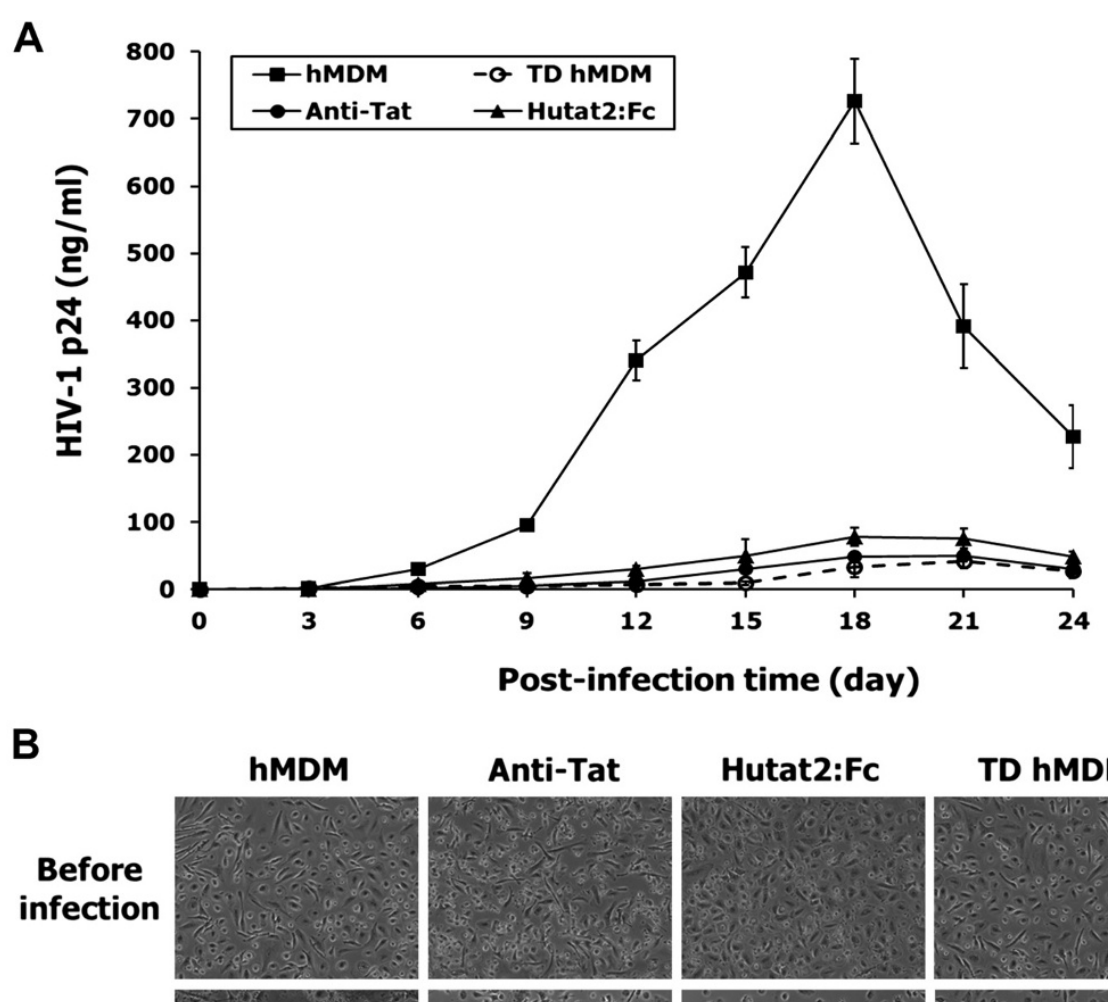

TD hMDM
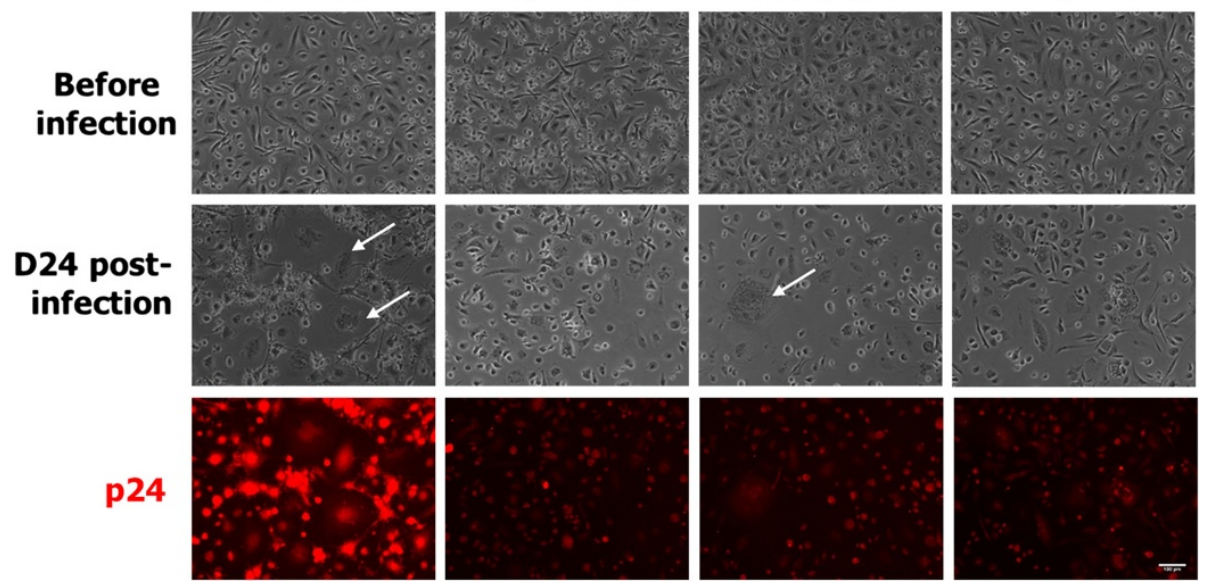

Figure 5 Reducing of HIV-1 replication by lentivirus-mediated expression of Hutat2:Fc in primary hMDM. (A) Kinetics of HIV-1 Ba-L $_{\text {replications }}$ (HIV-1 p24 levels). The data showed a significant reduction of HIV-1 replication in both the TD-hMDM and Hutat2:Fc culture groups as compared to hMDM $(P<0.01)$, but no statistical difference among TD-hMDM, Hutat2:Fc, and Anti-Tat groups $(P>0.05)$. (B) Lentiviral vectors HR-Hutat2 transduction suppresses HIV-1 cytopathicity and the expression of p24 in hMDM cultures. Normal hMDM and HR-Hutat2 transduced hMDM were exposed to $\mathrm{HIV}-1_{\mathrm{Ba}-\mathrm{L}}$ and examined before and on day 24 post-viral infection using a 10x objective. It can be readily appreciated that either HR-Hutat2 transduction or Hutat2:Fc strongly suppressed HIV-1-mediated cytopathic effects, resulting in a reduction in the number of giant cells in the culture. In addition, HIV-1 p24 immunofluorescent staining showed that HR-Hutat2 transduction and Hutat2:Fc reduced the expression of HIV-1 p24 intracellularly. Images were acquired as described in Figure 1. hMDM, Normal hMDM; TD-hMDM, HR-Hutat2 transduced hMDM; Anti-Tat, Non-transduced hMDM treated with anti-HIV-1 Tat antibody; Hutat2,Fc, Normal hMDM treated with conditioned medium from HR-Hutat2 transduced hMDM; D24 post-infection, Day 24 post-HIV-1-infection; P24, HIV-1 p24 immunofluorescent staining; White arrow, HIV-1-induced cytopathic effect. The blood of three donors was used in this assay. Results represent mean values from triple independent experiments and error bars denote the s.e.m. Scale bar $=100 \mu \mathrm{m}$.

related pro-inflammatory cytokine genes, apoptosisrelated genes, tumor-related genes, cell signal transduction genes, and cell surface receptor genes (Table 1) between normal and HR-Hutat2-transduced hMDM on day 9 post-transduction. Differential gene expression was considered "significant" when the normalized fold change of samples versus control was $>2$ (up-regulated) or $<0.5$ (down-regulated). Twelve out of 15 genes retained their expression at the same level in transduced
hMDM at a MOI of 10 or 50 compared with normal hMDM (Figure 6A). However, the change of gene expression level was detected in three genes, IL8, STAT1, and indoleamine-pyrrole 2,3-dioxygenase (IDO)1. STAT1 was $3.36 \pm 0.34$-fold up-regulated in the MOI 10 group and $4.29 \pm 0.77$-fold up-regulated in the MOI 50 group as compared to non-transduced hMDM $(P<0.01)$. It was $326.8 \pm 56.5$ - and $409.3 \pm 86.3$-fold up-regulated for IDO1 gene expression level in transduced hMDM at a MOI of 


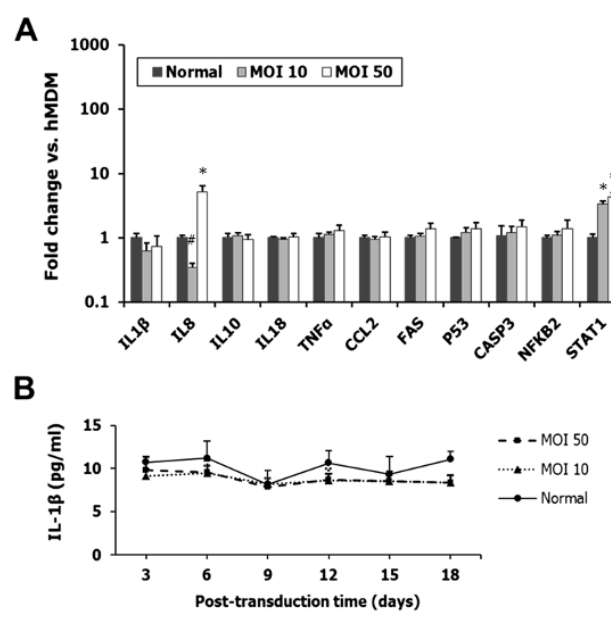

D

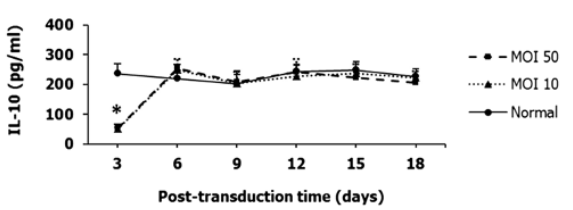

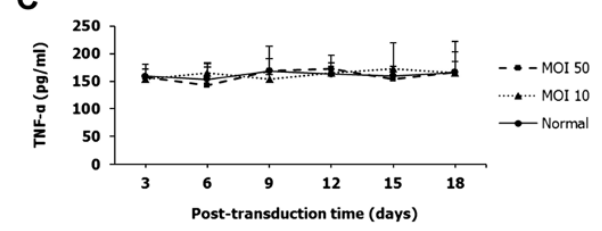

E

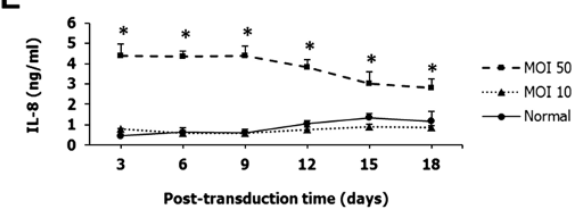

Figure 6 The effects of transduction with lentiviral vector HR-Hutat2 on the gene expression of human macrophage-related functional and regulatory genes and on kinetics of pro-inflammatory cytokines IL1 $\beta$, IL8, IL10, and TNF-a. Human monocyte-derived macrophages (hMDM) were differentiated from isolated peripheral blood mononuclear cells in M-CSF-containing medium. On day 7 and day 8 in vitro (DIV 7 and DIV 8), hMDMs were transduced with HR-Hutat2 vector at a MOI of 10 or 50. Total RNA was extracted from non-transduced hMDM (Normal) and transduced hMDM on day 9 post-transduction. Cell culture mediums were collected every 3 days post-transduction. (A) Comparative analysis of the transcriptional profiling of 15 hMDM-related functional and regulatory genes by qRT-PCR. Among the 15 genes, only the transcription of IL8, STAT1, and IDO1 genes changed. (B-E) Sequential changes of IL1 $\beta$, IL10, IL8, and TNF-a levels in the supernatants of normal and transduced hMDMs at a MOl of 10 or 50. Normal, Non-transduced hMDM; MOI 10, hMDM transduced with HR-Hutat2 at the MOI of 10; MOI 50, hMDM transduced with HR-Hutat2 at the $\mathrm{MOI}$ of $50 .{ }^{*} P<0.01,{ }^{\#} P<0.05$ compared with normal. Results shown represent mean values from three independent experiments. Error bars denote the s.e.m.

10 and 50, respectively $(P<0.01)$. The expression of IL8 increased by $5.2 \pm 1.2$-fold for the transduction at a MOI of $50(P<0.01)$ as compared to non-transduced hMDM.

Furthermore, to confirm whether the differential gene expression would relate to the protein translation, we sequentially evaluated four pro-inflammatory cytokines, IL1 $\beta$, IL8, IL10, and TNF- $\alpha$ levels in the conditioned medium of transduced and non-transduced hMDM. Consistently with the results of gene expression profiling, the levels of IL1 $\beta$ and TNF- $\alpha$ in the supernatants of both transduced hMDM groups did not change significantly on each post-transduction day as compared to non-transduced hMDM (Figure 6B,C). The release of IL10 in each transduced hMDM decreased about 4-fold on day 3 post-transduction $(51.7 \pm 3.6 \mathrm{pg} / \mathrm{mL}$ in the MOI 10 group and $54.5 \pm 11.2 \mathrm{pg} / \mathrm{mL}$ in the MOI 50 group, compared to $236.4 \pm 33.5 \mathrm{pg} / \mathrm{mL}$ in the nontransduced hMDM group), which returned to normal levels from day 6 post-transduction and maintained these normal levels on each following day (Figure 6D). The IL8 levels in the supernatants were increased on each of the post-transduction days in the MOI 50 group, which was consistent with the up-regulated IL8 gene expression. However, in the MOI 10 group, although the IL8 gene expression level was slightly downregulated, there was no significant change for the secretion of IL8 in the medium compared to the normal control (Figure 6E).

\section{Discussion}

This study had provided evidence for the anti-Tat Hutat2:Fc neutralizing strategy to successfully attenuate HIV-1 Tat-induced neurotoxicity in vitro. Specifically, we cloned the Hutat2:Fc construct into a lentiviral vector to transduce human cell lines of both neuron and monocyte origins, as well as primary hMDM. Then, we characterized the Hutat2:Fc expression, secretion, and specificity to recognize HIV-1 Tat ${ }_{86}$. The Hutat2:Fc fusion protein not only protected neurons from HIV-1 Tat-induced neurotoxicity, but also protected hMDM against $\mathrm{HIV}-1_{\mathrm{Ba}-\mathrm{L}}$ infection in vitro. These results provided proof-of-concept evidence for a novel therapeutic approach against HAND through utilizing hMDM as a therapeutic gene delivery vehicle following transduction with an HIV-1-based lentiviral vector that expresses humanized anti-HIV-1 Tat Hutat2:Fc. 
Although the causes of HAND are still unclear, there is a general agreement that the pathogenic mechanisms of HAND are induced by neurotoxic HIV-1 proteins, including Tat, and by pro-inflammatory cytokines and chemokines, as well as NO produced by HIV-1-infected macrophages and glial cells [27-29,34-36,45-47]. Therefore, an ideal therapeutic strategy for HAND is to maximize inhibition of HIV-1 infection and replication in the CNS, as well as to reduce the release of proinflammatory products. The current approach for the treatment of HAND is cART [1,48]. However, cART cannot completely prevent HIV replication in the CNS, which is why HIV persists at low-levels in the brain and continues to drive neurodegeneration [1]. Additionally, different antiretroviral agents show variable penetration into the CNS. Although a CPE rank system was formalized in order to improve the efficacy of cART for HAND $[7,48]$, several studies have suggested CPE is a flawed metric. A cART regimen with a high CPE score did not improve neurocognitive performance in individuals with HAND, but rather increased the risk of HIV dementia $[10,11]$. Thus, adjuvant therapies such as neuroprotective and anti-inflammatory approaches are being explored [1]. To date, adjuvant therapy for HAND is facing three major challenges: which targets to choose, what kinds of reagents to deliver, and how to deliver therapeutic reagents into the CNS.

In this study, the choice of utilizing a humanized antiHIV-1 Tat scFv Hutat2 as a therapeutic candidate was based on the evidence that Hutat 2 had been shown to be highly effective in inhibiting HIV replication both in vitro and in vivo [22,37-39]. In terms of pathophysiology, both intracellular and extracellular Tat proteins play an important role in the development of HAND. Tat is a potent activator of viral transcription, which promotes the replication of HIV-1 and the production of other neurotoxic viral proteins including gp120 from HIV-1-infected cells [49,50]. Although Tat is normally processed in the nucleus, it is also secreted from infected cells to affect neighboring cells by causing direct neurotoxicity, bystander glial cell activation, and releasing of pro-inflammatory cytokines, chemokines, and NO [28,34-36,51]. HIV-1 Tat proteins from primary virus isolates are encoded by two exons, which consist of 1 to 86 or 1 to 101 amino acids, respectively [52-54]. The LAI/Bru strain of HIV-1 (Clade B) encodes a Tat protein which consists of 1 to 86 amino acids due to a premature stop codon within the second tat exon [55]. HIV-1 Clade $\mathrm{C}$ infections are more prevalent in sub-Saharan Africa and Asia, whereas HIV-1 Clade B is the predominant subtype in the USA, Canada, Western Europe, and Australia [56]. In addition, the differences in neurotoxicity of Tat are clade-specific. Several studies have demonstrated that recombinant Tat clade $\mathrm{C}$ has an attenuated potential for direct neurotoxicity [57-59] and a decreased ability to induce indirect neurotoxicity $[58,60,61]$. In a previous study, Tat-transgenic mice were used as an animal model for HAND in which a gene that codes for Tat 1 to 86 amino acids was specifically integrated into astrocytes, producing brain-specific expression $[62,63]$. In agreement with others and our previous work, Tat ${ }_{86}$ at a concentration of $500 \mathrm{nM}$ or above induced neuron death [24,64]. Thus, in order to evaluate the protective effect of Hutat2: Fc, we used $500 \mathrm{nM}$ of $\mathrm{Tat}_{86}$ (Clade B) to produce a dynamic range of cytotoxicity.

An HIV-1-based lentiviral vector is an effective gene transfer system for transducing both dividing and nondividing cells such as primary cultures of hMDM prepared from human whole blood. To inactivate both the intracellular and extracellular Tat, a self-inactivating HIV-1-based lentiviral vector expressing anti-Tat Hutat2: Fc with a $\mathrm{N}$-terminal IgG leader sequence was used to transduce human cell lines and primary hMDM. In the present study, anti-Tat was produced in the scFv:Fc format as opposed to $\mathrm{scFv}$ or to full-length IgG for gene transfer for several reasons. First, the Fc domain folds independently and can improve the solubility and stability of the partner molecule both in vitro and in vivo, thus remarkably increasing the fusion protein half-life, which prolongs therapeutic activity $[65,66]$. In addition, the Fc domain can prolong serum half-life by binding to the neonatal Fc receptor $[67,68]$. Second, the Fc domain can increase the expression and secretion of proteins in mammalian cells to a high level $[69,70]$. Third, the Fc region allows for easy cost-effective quantification by ELISA which was used in this study and purification by protein-G/A affinity chromatography [66]. Fourth, the small size of the scFv:Fc format may allow greater tissue penetration than a whole IgG [20,71]. The IgG leader in the construct was used to direct the expression of Hutat2:Fc to the endoplasmic reticulum, where Hutat2: Fc can be secreted into cell culture medium more efficiently [22]. As evidenced in this study, the transduction and expression of Hutat2:Fc in HTB-11, U937, and hMDM cells led to detectable high levels of protein in the cell culture medium. In HTB-11 and U937 cells, the Hutat2:Fc gene was stably expressed for more than 20 passages and sustained at a high level, reaching to $600 \mathrm{ng} / \mathrm{mL}$ in HTB-11 and $33 \mathrm{ng} / \mathrm{mL}$ in U937 within a 24-hour cultivation time. Moreover, we confirmed the accumulation of the secreted fusion protein in the culture mediums from these transduced cell lines. Spininfection was reported as an efficient method to improve the transduction efficiency for cell suspensions [72]. It was noticed that, although the transduction efficiency of monocytic U937 cells was increased to more than 95\% after the second-round of spin-infection, the Hutat2:Fc gene expression and the protein secretion levels were 
much lower than those detected from transduced HTB11 cells. Among transduced HTB-11 and U937 cell lines and primary hMDM, the highest Hutat2:Fc transcription level was found in transduced HTB-11 cells, which is 162.5-fold higher than that in transduced hMDM and 18.0-fold higher than that in transduced U937. Similarly, the difference of the concentration of Hutat2:Fc in conditioned medium was also confirmed. This could partly explain why the protection effects of the conditioned medium from transduced hMDM are not as high as those from transduced HTB-11 and anti-Tat antibody in vitro. A potential explanation for this difference in protein expression levels is that HTB-11 cells may have a higher integrated copy number of the target gene than myeloid lineage cells, including U937 cell lines and primary hMDM. This is consistent with previous observations that neural cells are more readily transduced by HIV-1-based vectors than cells of myeloid lineage such as macrophages and microglia [24,73]. In addition, the intercellular dNTP level was reported to be vital for HIV-1 reverse transcription and viral replication [74]. However, the concentration of intercellular dNTP in non-dividing macrophages was very low compared to that of dividing cells $[75,76]$. Thus, the HIV-1-based vector transduction efficiency and the Hutat2:Fc gene expression level in primary hMDM were not expected to be as high as those in HTB-11 and U937 cells. Alternatively, it is possible that there may be other intrinsic differences in the ability of different cell types to produce and secrete Hutat2:Fc.

In terms of delivering therapeutic genes into the CNS, there are several candidate methods, including direct invasive injection of viral vectors or genetically modified cells into the cerebrum, which compromise the BBB and produce a reliable gene expression efficiency [77-79]. However, these are not viable therapeutic approaches for HAND in human since they are often accompanied with traumatic brain injuries and repetitive administration may be required. Non-invasive CNS delivery methods are more viable. Circulating monocytes and monocytederived macrophages are known to migrate across the $\mathrm{BBB}$ and to enter the CNS under normal physiological conditions and certain pathological circumstances [80-84]. Moreover, some of these cells can subsequently mature into long-lived tissue-resident brain macrophages and microglia $[84,85]$. Thus, monocytes/MDMs have the potential to deliver therapeutic reagents or genes into the CNS as "Trojan horses" [86]. Some advantageous attempts have been made for the treatment of neurodegenerative diseases including HAND. For example, it was reported that genetically-modified circulating $\mathrm{CD} 11 \mathrm{~b}^{+}$cells (largely monocytes) were used to deliver and express the protease neprilysin gene into the CNS to arrest amyloid deposition in an Alzheimer's disease transgenic murine model [82].
Genetically-modified macrophages were utilized to deliver glial cell-derived neurotrophic factor for the treatment of Parkinson's disease in a murine model [87]. Nanoformulated antiretroviral drugs were also delivered into the brain by MDMs in a murine model of HAND [80]. Thus, in this study, we explored a promising therapeutic strategy through the use of MDMs as a potential gene delivery vehicle.

We demonstrated that lentiviral vector-mediated gene transfer could be successfully used in hard-to-transduce monocytic cell lines such as U937 and primary hMDM, which led to stable expression of Hutat2:Fc fusion protein. Not only was the expression stable at a high level over time, but also the secreted Hutat2:Fc from different transduced cells was shown to be consistently biologically active. DIBA analysis and Western blotting demonstrated that the secreted Hutat2:Fc bound directly to HIV-1 Tat $_{86}$ as a full-length anti-Tat monoclonal antibody, whereas the A3H5:Fc control could not. In addition, Hutat2:Fc expressed from lentiviral vector-transduced HTB-11 or hMDM (at final concentrations of $536 \mathrm{ng} / \mathrm{mL}$ for HTB-Hutat2 and $42.8 \mathrm{ng} / \mathrm{mL}$ for hMDM-Hutat2) conferred significant neuroprotection against neurotoxicity induced by HIV-1 Tat $_{86}$ in the human neuronal cell line HTB-11 and primary murine neuron culture. Moreover, it has been reported that although anti-Tat antibody could not fully block HIV infection, it could suppress HIV replication [88-90]. As shown in this study, Hutat2:Fc in conditioned medium from hMDM-Hutat2 at a final concentration about $106.9 \mathrm{ng} / \mathrm{mL}$ was able to suppress HIV- $1_{\mathrm{Ba}-\mathrm{L}}$ replication in primary hMDM. Additionally, HRHutat2-transduced hMDM presented resistance against viral replication. These findings suggest that delivery of genetically-modified primary MDM expressing Hutat2:Fc to the CNS to attenuate neuro-inflammation, suppress HIV-1 replication, and reduce the spread of viral infection would be a very promising therapeutic strategy against HIV-1 Tat-induced neurotoxicity. However, it should be noticed that the production of Hutat2:Fc in transduced hMDM was not as high as in transduced neuronal HTB11 cells. The production of lower amounts of Hutat2:Fc protein reduced the neuroprotective effect. Furthermore, it is unclear how efficiently transduced MDM would get into the CNS and how many transduced MDM would be necessary to produce a significant effect on the development of neuropathology. Another limitation of this study is that the HIV challenge experiment was an acute HIV infection ex vivo. We did not evaluate the effect of Hutat2: Fc on viral suppression in a chronic HIV infection model, especially when the virus was already suppressed by antiretroviral regimens. Further animal studies will be needed to explore these issues.

The self-inactivating lentiviral vector-based gene therapy is relatively safe and some vectors are currently being evaluated in clinical trials [91]. Our findings also 
showed that the transduced cell line HTB-11 did not result in any measurable alternation in cell viability. However, MDM, considered as plastic cells, are double-edged swords for anti-infectious immunity as well as tissue injury and repair. As with T cells, monocytes can be activated and polarized into either the classically activated pro-inflammatory (M1) macrophages subtype, or an anti-inflammatory alternatively activated (M2) subtype according to their micro-environments [92-94]. Defining macrophages based on their specific functional activities is a more appropriate approach [94]. Granulocyte macrophage colony stimulating factor (GM-CSF) and M-CSF are involved in the differentiation of monocytes to macrophages $[92,93]$. Specifically, GM-CSF causes initial differentiation of monocytes towards the M1 macrophage subtype with a pro-inflammatory cytokine profile (e.g., TNF- $\alpha$, IL1 $\beta$, IL6, IL23), whereas M-CSF treatment produces an anti-inflammatory cytokine (e.g., IL10, TGF- $\beta$ ) profile similar to M2 macrophages [92,93]. Our findings also confirmed that M-CSF stimulated the monocytes within the peripheral blood mononuclear cell population differentiation toward an M2-like phenotype with a high production of IL10 (Figure 6C), which would be more beneficial to the CNS wound healing. However, this polarization can be switched to an M1-like phenotype under the circumstance of acute microbe infection [95]. Thus, we investigated the potential immune-activation induced by lentiviral vector transduction. Our results indicated that the gene expression level of eight immunerelated genes, including $I L 1 \beta, I L 10, I L 18, T N F-\alpha, C C L 2$, TLR1, IFGR2, and CCR5, and four cell cycle regulator, apoptosis, and signal transduction-related genes, including Fas, P53, CASP3, and NFKB2, in 15 candidate genes were not significantly changed following transduction as compared to non-transduced hMDM (Figure 6A). No change was observed in the concentrations of IL1 $\beta$ and TNF- $\alpha$ after transduction, which further confirmed the results of qRT-PCR (Figure 6B,C). Transduction with HR-Hutat2 resulted in a dramatical decrease of IL10 production on day 3 post-transduction (Figure 6D). However, this change recovered from day 6 post-transduction and other cytokines related to M1 polarization state, such as IL1 $\beta$ and TNF- $\alpha$, did not significantly change during the following days (Figure 6B-D). This means that lentiviral transduction induced a transient decrease of IL10 production, but did not completely switch the polarization of hMDM from the M2 to M1 phenotype.

However, we also found some atypical M1-skewed polarization profiles in response to lentiviral transduction. Notably, three genes, including IL8, STAT1, and IDO1, were up-regulated in transduced hMDM at a MOI of 50 (Figure 6A). Although the IL8 mRNA expression was down-regulated, the release of IL8 did not change in transduced hMDM at a MOI of 10 (Figure 6E).
IL8 is a pro-inflammatory cytokine, which induces phagocytosis and chemotaxis in target cells, primarily neutrophils, and also other granulocytes, causing them to migrate toward the site of infection. STAT1 is a member of the signal transducers and activators of transcription family, which up-regulated when macrophage polarized toward an M1 phenotype [96]. IDO encoded by $I D O 1$ gene is the rate-limiting enzyme of tryptophan catabolism through the kynurenine pathway, thus causing depletion of tryptophan. It has been reported that IDO1 gene expression was up-regulated and IDO activity was increased in HIV-1 simian immunodeficiency virus (SIV)-, and feline immunodeficiency virus-infected $\mathrm{T}$ cells as well as macrophages [97-100]. Moreover, HIV-1 Tat was proved to increase expression of IDO in murine organotypic hippocampal slice cultures and in human primary astrocytes $[101,102]$. IDO activation was related to the modulation of the immune response and neuropathogenic effects in HIV infection. For example, several findings suggested that an increase of functional IDO enzymatic activity is correlated with immunosuppression by its ability to inhibit lymphocyte proliferation and with increased production of neurotoxins, such as kynurenine and quinolinic acid, in the brain [97,103-105]. In SIVinfected macaques, mRNA expression of cytotoxic $\mathrm{T}$ lymphocytes antigen-4 (CTLA-4) and FoxP3, markers of regulatory $\mathrm{T}$ cells $\left(\mathrm{T}_{\text {reg }}\right)$, as well as IDO, were increased in the spleens, mesenteric lymph nodes, colons, and jejuna, and were directly correlated to SIV RNA in the same tissues [99]. CTLA-4 blockade decreased IDO and viral RNA expression, and increased the effector function of both SIV-specific $\mathrm{CD} 4^{+}$and $\mathrm{CD}^{+} \mathrm{T}$ cells in lymph nodes [106]. Inhibition of IDO activity led to enhanced generation of HIV-1-specific cytotoxic T lymphocytes, leading to elimination of HIV-1-infected macrophages in the CNS [103]. These data indicated increased IDO expression or activity might favor HIV/SIV replication and the establishment of viral reservoirs in lymphoid tissues and in the CNS. However, a few studies showed inconsistent effects regarding the up-regulated IDO expression on viral replication. Although IDO transcripts were increased in HIV encephalitis, IDO activation would likely suppress intracellular viral replication in astrocytes [107]. IDO function probably dissociated from protein expression, which would be determined by the local CNS cytokine and NO microenvironment [107]. A recent study found that the up-regulation of IDO1 mRNA expression was likely contributed to macrophage M1 polarization [93]. Furthermore, M1 polarization of hMDM would restrict HIV-1 replication in pre- and post-integration steps [108]. Hence, the role of IDO in HIV-induced inflammation of the CNS was not completely clear and probably double-edged. In this study, the HIV-1-based lentiviral vector also induced an 
up-regulated IDO1 gene expression in hMDM. Moreover, similar gene expression profiling was found in both HR-Hutat2-transduced hMDM at the different MOIs and HR-A3H5-transduced hMDM (data not shown). These findings indicated that the up-regulation of IDOI gene expression was induced by a vector transduction process independently, and not due to the presence of Hutat2:Fc. Although vector transduction promoted the expression of IDO1 gene and stimulated hMDM polarization towards atypical M1-skewed polarization profiles, the functions of IDO and M1-skewed profiles in neuropathogenesis and viral remission were microenvironmentdependent and require further investigation. In addition, our current study did not observe any significant neurotoxicity from the conditioned mediums in the neuron protection assay. In other words, the neuron protective effects of Hutat2:Fc probably have overpowered the potential side effects induced by lentiviral vector transduction.

To conclude, this study provides a preliminarily functional evaluation of anti-HIV-1 Tat Hutat2:Fc and transduced cells against Tat ${ }_{86}$-induced neurotoxicity and HIV-1 challenge in vitro. Further investigations on in vivo neuronal protection and HIV-1 inhibition of transduced monocytes/macrophages for gene delivery into the CNS are required. On the other hand, the vector transduction induced alternation on the expression of several genes, including IL8, STAT1, and IDO1, presenting potential immunological effects on transduced macrophages and the clearance of virus in the CNS. Thus, examining the potential side effects of exploring this technology as a therapeutic strategy in HAND animal models is definitely essential for future studies.

\section{Conclusions}

Our study demonstrated that an HIV-1-based lentiviral vector could efficiently transfer therapeutic the antiHIV-1 Tat Hutat2:Fc gene into human neuronal and monocytic cell lines as well as primary cultures of hMDM. Hutat2:Fc can be stably expressed and secreted from the transgenic cells and can protect neurons against HIV-1 Tat ${ }_{86}$-induced neurotoxicity, and suppress but not fully block HIV-1 $1_{\mathrm{Ba}-\mathrm{L}}$ replication in both nontransduced and transduced hMDM in vitro. Moreover, lentiviral transduction did not result in any significant changes in cytomorphology and cell viability. Although the expression of IL8, STAT1, and IDO1 genes was upregulated in transduced hMDM, such alternation in these gene expression profiles did not affect the neuroprotective effect of Hutat2:Fc. While much work is still required to develop a viable approach for application in patients, these findings provide interesting insights for utilizing Hutat2:Fc gene-modified monocytes/macrophages as a potential novel therapeutic strategy for HAND.

\section{Additional files}

\begin{abstract}
Additional file 1: Schematic map of the HIV-1-based transfer plasmid. The HIV-1-based lentiviral vector was used to express enhanced green fluorescent protein (EGFP), with either the therapeutic anti-HIV-1 Tat single chain fragment intrabody (scFv) Hutat2:Fc fusion protein (HR-Hutat2), or the control scFv A3H5:Fc fusion protein (HR-A3H5); the fusion proteins used the human IgG leader to direct the expression to the endoplasmic reticulum and used the Fc domain to increase stability and to tag protein expression. LTR, Long terminal repeat; $\psi$, Packaging signal; SD, Splice donor; SA, Splice acceptor; CMV, Cytomegalovirus promoter; scFv:Fc, The construct encoding the anti-Tat Hutat2 fused to Fc or the anti-Epstein-Barr virus latent membrane protein 1 (LMP-1) A3H5 fused to Fc; Fc, Hinge domain from lgG1 and the Fc domain from human IgG3; IRES, Internal ribosome entry site; GFP, Green fluorescent protein. Primers used for molecular cloning: forward/ reverse, 5'-CCGCTCGAGCGGGCCGGCCATGGCCCAGGTGCA-3'/5'-

CGCGGATCCGCGTTAAATCATTTACCCGGAGACAGG-3' (italics indicate the restriction enzyme cutting site).
\end{abstract}

Additional file 2: CD14 staining for primary culture of hMDM. Afte three washings with PBS, primary culture of hMDM was stained with a human CD14 monoclonal antibody conjugated with R-phycoerythrin on day 6 in vitro (DIV 6). The purity of hMDM culture in vitro was calculated to be $>98 \%$

Additional file 3: Specific binding of Hutat2:Fc from transduced cells to HIV-1 Tat $_{\mathbf{8 6}}$ by Western blot assay. HIV-1 Tat ${ }_{86}(14 \mathrm{kDa})$ was separated by SDS-PAGE electrophoresis and transferred onto NCM. Each NCM was incubated with the conditioned mediums from HR-Hutat2transduced cells (HTB-Hutat2, U937-Hutat2, and hMDM-Hutat2) at $4^{\circ} \mathrm{C}$ overnight followed by incubation with rabbit anti-human $\lg \mathrm{G}_{(\mathrm{H}+\mathrm{L})}$ and goat anti-rabbit IgG-HRP conjugated antibodies, respectively. Specific binding was visualized by the color deposition on the NCM when DAB was added. The Tat-containing NCM incubated with the conditioned medium from HR-A3H5-transduced HTB-11 served as a negative control (HTB-A3H5), while the Tat-containing membrane incubated with rabbit anti-Tat serum served as a positive control (Pos Ctl). The lane loaded with Tat dilution buffer was used as a blank control (BLK Ctl).

\section{Abbreviations}

A3H5:Fc: Anti-Epstein-Barr virus latent membrane protein 1 scFv A3H5:Fc fusion protein; BBB: Blood-brain barrier; BSA: Bovine serum albumin; CART: Combined antiretroviral therapy; CNS: Central nervous system; CPE: CNS penetration-effectiveness; CTLA-4: Cytotoxic T lymphocytes antigen-4; DAB: 3,3-diaminobenzidine tetrahydrochloride; DIBA: Dot-immunobinding assay; DIV: Days in vitro; ELISA: Enzyme-linked immunosorbent assay; FBS: Fetal bovine serum; GM-CSF: Granulocyte macrophage colony stimulating factor; HAND: HIV-associated neurocognitive disorder; hMDM: Human monocyte-derived macrophages; HRP: Horseradish peroxidase; Hutat2:Fc: Humanized anti-Tat scFv:Fc fusion protein; IDO: Indoleamine-pyrrole 2,3-dioxygenase; IRES: Internal ribosome entry site; MAP2: Microtubule-associated protein 2; M-CSF: Macrophage colony stimulating factor; MDM: Monocyte-derived macrophages; MOI: Multiplicity of infection; NCM: Nitrocellulose membrane; NO: Nitric oxide; RT: Room tempreature; scFv: Single-chain variable fragment intrabodies; SDS: Sodium dodecyl sulfate; TBST: Tris-buffered saline containing 0.05\% Tween 20; $\mathrm{T}_{\text {reg: }}$ : Regulatory T cells; TUNEL: Terminal dexoynucleotidyl transferase-mediated dUTP nick end labeling.

\section{Competing interests}

The authors declare that they have no competing interests.

\section{Authors' contributions}

$Y L, Y S$, and WK conceived and designed the experiments. WK, HT, MMB, and YL performed the experiments. WK and HT analyzed the data. CW, YSH, SS, and WM contributed with reagents/materials/analysis tools. WK, HT, YL, YS, and WM wrote the paper. WK, YS, and YL performed the study consultation. All authors read and approved the final manuscript. 


\section{Acknowledgments}

This study was supported by grants from the National Institutes of Health (R01 MH079717 and S11NS043499). The following reagents were obtained through the NIH AIDS Reagent Program, Division of AIDS, NIAID, NIH: HIV-1 Tat (Cat\#2222), rabbit antiserum to HIV-1 Tat from Dr. Bryan Cullen (Cat\#705), HIV-1 Tat monoclonal antibody (1D9) from Dr. Dag E. Helland (Cat\#7377), monoclonal antibody to HIV-1 p24 from Dr. Susan Zolla-Pazner (Cat\#530), and HIV-1 Ba-L from Dr. Suzanne Gartner, Dr. Mikulas Popovic, and Dr. Robert Gallo (Cat\#510).

\section{Author details}

'Department of Infectious Diseases, Tangdu Hospital, The Fourth Military Medical University, 569 Xinsi Road, Xi'an, Shaanxi 710038, China. ${ }^{2}$ Department of Public Health Sciences, John A. Burns School of Medicine, University of Hawaii, 1960 East-west Road, Honolulu, HI 96822, USA. ${ }^{3}$ Department of Cancer Immunology and AIDS, Dana-Farber Cancer Institute, Harvard Medica School, 50 Brookline Avenue, Boston, MA 02215, USA. ${ }^{4}$ Hawaii Center for AIDS, John A. Burns School of Medicine, University of Hawaii, 651 Ilalo St. BSB, Suite 231, Honolulu, HI 96813, USA.

Received: 2 August 2014 Accepted: 5 November 2014

Published online: 22 November 2014

\section{References}

1. Clifford DB, Ances BM: HIV-associated neurocognitive disorder. Lancet Infect Dis 2013, 13:976-986.

2. Antinori A, Arendt G, Becker JT, Brew BJ, Byrd DA, Cherner M, Clifford DB, Cinque P, Epstein LG, Goodkin K, Gisslen M, Grant I, Heaton RK, Joseph J, Marder K, Marra CM, McArthur JC, Nunn M, Price RW, Pulliam L, Robertson KR, Sacktor N, Valcour V, Wojna VE: Updated research nosology for HIV-associated neurocognitive disorders. Neurology 2007, 69:1789-1799.

3. Heaton RK, Clifford DB, Franklin DR Jr, Woods SP, Ake C, Vaida F, Ellis RJ, Letendre SL, Marcotte TD, Atkinson JH, Rivera-Mindt M, Vigil OR, Taylor MJ, Collier AC, Marra CM, Gelman BB, McArthur JC, Morgello S, Simpson DM McCutchan JA, Abramson I, Gamst A, Fennema-Notestine C, Jernigan TL, Wong J, Grant I, CHARTER Group: HIV-associated neurocognitive disorders persist in the era of potent antiretroviral therapy: CHARTER Study. Neurology 2010, 75:2087-2096.

4. Kanmogne GD, Kuate CT, Cysique LA, Fonsah JY, Eta S, Doh R, Njamnshi DM, Nchindap E, Franklin DR Jr, Ellis RJ, McCutchan JA, Binam F, Mbanya D, Heaton RK, Njamnshi AK: HIV-associated neurocognitive disorders in sub-Saharan Africa: a pilot study in Cameroon. BMC Neurol 2010, 10:60.

5. Simioni S, Cavassini M, Annoni JM, Rimbault Abraham A, Bourquin I, Schiffer V, Calmy A, Chave JP, Giacobini E, Hirschel B, Du Pasquier RA: Cognitive dysfunction in HIV patients despite long-standing suppression of viremia. AIDS 2010, 24:1243-1250.

6. Thomas SA: Anti-HIV drug distribution to the central nervous system. Curr Pharm Des 2004, 10:1313-1324.

7. Letendre S, Marquie-Beck J, Capparelli E, Best B, Clifford D, Collier AC, Gelman BB, McArthur JC, McCutchan JA, Morgello S, Simpson D, Grant I, Ellis RJ, CHARTER Group: Validation of the CNS Penetration-Effectiveness rank for quantifying antiretroviral penetration into the central nervous system. Arch Neurol 2008, 65:65-70.

8. Alfahad TB, Nath A: Update on HIV-associated neurocognitive disorders. Curr Neurol Neurosci Rep 2013, 13:387.

9. Rao VR, Ruiz AP, Prasad VR: Viral and cellular factors underlying neuropathogenesis in HIV associated neurocognitive disorders (HAND). AIDS Res Ther 2014, 11:13.

10. Ellis RJ, Letendre S, Vaida F, Haubrich R, Heaton RK, Sacktor N, Clifford DB, Best BM, May S, Umlauf A, Cherner M, Sanders C, Ballard C, Simpson DM, Jay C, McCutchan JA: Randomized trial of central nervous systemtargeted antiretrovirals for HIV-associated neurocognitive disorder. Clin Infect Dis 2014, 58:1015-1022

11. Caniglia EC, Cain LE, Justice A, Tate J, Logan R, Sabin C, Winston A, van Sighem A, Miro JM, Podzamczer D, Olson A, Arribas JR, Moreno S, Meyer L, del Romero J, Dabis F, Bucher HC, Wandeler G, Vourli G, Skoutelis A, Lanoy E, Gasnault J, Costagliola D, Hernán MA, HIV-CAUSAL Collaboration: Antiretroviral penetration into the CNS and incidence of AIDS-defining neurologic conditions. Neurology 2014, 83:134-141.

12. Di Nunzio F, Felix T, Arhel NJ, Nisole S, Charneau P, Beignon AS: HIVderived vectors for therapy and vaccination against HIV. Vaccine 2012, 30:2499-2509.
13. Liang $X$, Casimiro DR, Schleif WA, Wang F, Davies ME, Zhang ZQ, Fu TM, Finnefrock AC, Handt L, Citron MP, Heidecker G, Tang A, Chen M, Wilson KA, Gabryelski L, McElhaugh M, Carella A, Moyer C, Huang L, Vitelli S, Patel D, Lin J, Emini EA, Shiver JW: Vectored Gag and Env but not Tat show efficacy against simian-human immunodeficiency virus 89.6P challenge in Mamu-A*01-negative rhesus monkeys. J Virol 2005, 79:12321-12331.

14. Someya $K$, Xin $K Q$, Ami Y, Izumi Y, Mizuguchi H, Ohta S, Yamamoto N, Honda M, Okuda K: Chimeric adenovirus type 5/35 vector encoding SIV gag and HIV env genes affords protective immunity against the simian/ human immunodeficiency virus in monkeys. Virology 2007, 367:390-397.

15. Peters BS: The basis for HIV immunotherapeutic vaccines. Vaccine 2001, 20:688-705.

16. Ahluwalia JK, Khan SZ, Soni K, Rawat P, Gupta A, Hariharan M, Scaria V Lalwani M, Pillai B, Mitra D, Brahmachari SK: Human cellular microRNA hsamiR-29a interferes with viral nef protein expression and HIV-1 replication. Retrovirology 2008, 5:117.

17. Nielsen MH, Pedersen FS, Kjems J: Molecular strategies to inhibit HIV-1 replication. Retrovirology 2005, 2:10

18. Novina CD, Murray MF, Dykxhoorn DM, Beresford PJ, Riess J, Lee SK, Collman RG, Lieberman J, Shankar P, Sharp PA: siRNA-directed inhibition of HIV-1 infection. Nat Med 2002, 8:681-686.

19. Wu C, Nerurkar VR, Lu Y: New insights into inhibition of human immunodeficiency virus type 1 replication through mutant tRNALys3. Retrovirology 2013, 10:112.

20. Abdel-Motal UM, Sarkis PT, Han T, Pudney J, Anderson DJ, Zhu Q, Marasco WA: Anti-gp120 minibody gene transfer to female genital epithelial cells protects against HIV-1 virus challenge in vitro. PLoS One 2011, 6:e26473.

21. Bouchet J, Basmaciogullari SE, Chrobak P, Stolp B, Bouchard N, Fackler OT, Chames $P$, Jolicoeur $P$, Benichou S, Baty D: Inhibition of the Nef regulatory protein of HIV-1 by a single-domain antibody. Blood 2011, 117:3559-3568.

22. Braun SE, Taube R, Zhu Q, Wong FE, Murakami A, Kamau E, Dwyer M, Qiu G, Daigle J, Carville A, Johnson RP, Marasco WA: In vivo selection of CD4(+) $T$ cells transduced with a gamma-retroviral vector expressing a singlechain intrabody targeting HIV-1 tat. Hum Gene Ther 2012, 23:917-931.

23. Theisen DM, Pongratz C, Wiegmann K, Rivero F, Krut O, Kronke M: Targeting of HIV-1 Tat traffic and function by transduction-competent single chain antibodies. Vaccine 2006, 24:3127-3136.

24. Cao S, Wu C, Yang Y, Sniderhan LF, Maggirwar SB, Dewhurst S, Lu Y: Lentiviral vector-mediated stable expression of sTNFR-Fc in human macrophage and neuronal cells as a potential therapy for neuroAIDS. J Neuroinflammation 2011, 8:48.

25. Tong J, Buch S, Yao H, Wu C, Tong HI, Wang Y, Lu Y: Monocytes-derived macrophages mediated stable expression of human brain-derived neurotrophic factor, a novel therapeutic strategy for neuroAIDS. PLOS One 2014, 9:e82030.

26. Ensoli B, Buonaguro L, Barillari G, Fiorelli V, Gendelman R, Morgan RA, Wingfield P, Gallo RC: Release, uptake, and effects of extracellular human immunodeficiency virus type 1 Tat protein on cell growth and viral transactivation. J Virol 1993, 67:277-287.

27. Banks WA, Robinson SM, Nath A: Permeability of the blood-brain barrier to HIV-1 Tat. Exp Neurol 2005, 193:218-227.

28. Buscemi L, Ramonet D, Geiger JD: Human immunodeficiency virus type-1 protein Tat induces tumor necrosis factor-alpha-mediated neurotoxicity. Neurobiol Dis 2007, 26:661-670.

29. Agrawal L, Louboutin JP, Reyes BA, Van Bockstaele EJ, Strayer DS: HIV-1 Tat neurotoxicity: a model of acute and chronic exposure, and neuroprotection by gene delivery of antioxidant enzymes. Neurobiol Dis 2012, 45:657-670.

30. Price TO, Ercal N, Nakaoke R, Banks WA: HIV-1 viral proteins gp120 and Tat induce oxidative stress in brain endothelial cells. Brain Res 2005 1045:57-63.

31. Magnuson DS, Knudsen BE, Geiger JD, Brownstone RM, Nath A: Human immunodeficiency virus type 1 tat activates non- $\mathrm{N}$-methyl-D-aspartate excitatory amino acid receptors and causes neurotoxicity. Ann Neurol 1995, 37:373-380.

32. Chandra T, Maier W, Konig HG, Hirzel K, Kogel D, Schuler T, Chandra A Demirhan I, Laube B: Molecular interactions of the type 1 human immunodeficiency virus transregulatory protein Tat with $\mathrm{N}$-methyl-daspartate receptor subunits. Neuroscience 2005, 134:145-153.

33. Self RL, Mulholland PJ, Nath A, Harris BR, Prendergast MA: The human immunodeficiency virus type- 1 transcription factor Tat produces 
elevations in intracellular $\mathrm{Ca} 2+$ that require function of an N-methyl-Daspartate receptor polyamine-sensitive site. Brain Res 2004, 995:39-45.

34. Kim TA, Avraham HK, Koh YH, Jiang S, Park IW, Avraham S: HIV-1 Tatmediated apoptosis in human brain microvascular endothelial cells. J Immunol 2003, 170:2629-2637.

35. Campbell GR, Watkins JD, Singh KK, Loret EP, Spector SA: Human immunodeficiency virus type 1 subtype $C$ Tat fails to induce intracellular calcium flux and induces reduced tumor necrosis factor production from monocytes. J Virol 2007, 81:5919-5928.

36. Yang Y, Wu J, Lu Y: Mechanism of HIV-1-TAT induction of interleukin1 beta from human monocytes: Involvement of the phospholipase C/protein kinase C signaling cascade. J Med Virol 2010, 82:735-746.

37. Mhashilkar AM, LaVecchio J, Eberhardt B, Porter-Brooks J, Boisot S, Dove JH, Pumphrey C, Li X, Weissmahr RN, Ring DB, Ramstedt U, Marasco WA: Inhibition of human immunodeficiency virus type 1 replication in vitro in acutely and persistently infected human CD4+ mononuclear cells expressing murine and humanized anti-human immunodeficiency virus type 1 Tat singlechain variable fragment intrabodies. Hum Gene Ther 1999, 10:1453-1467.

38. Poznansky MC, La Vecchio J, Silva-Arietta S, Porter-Brooks J, Brody K, Olszak IT, Adams GB, Ramstedt U, Marasco WA, Scadden DT: Inhibition of human immunodeficiency virus replication and growth advantage of CD4+ T cells and monocytes derived from CD34+ cells transduced with an intracellular antibody directed against human immunodeficiency virus type 1 Tat. Hum Gene Ther 1999, 10:2505-2514.

39. Marasco WA, LaVecchio J, Winkler A: Human anti-HIV-1 tat sFv intrabodies for gene therapy of advanced HIV-1-infection and AIDS. J Immunol Methods 1999, 231:223-238.

40. Zeng L, Yang S, Wu C, Ye L, Lu Y: Effective transduction of primary mouse blood- and bone marrow-derived monocytes/macrophages by HIVbased defective lentiviral vectors. J Virol Methods 2006, 134:66-73.

41. Wu C, Lu Y: Inclusion of high molecular weight dextran in calcium phosphate-mediated transfection significantly improves gene transfer efficiency. Cell Mol Biol (Noisy-le-grand) 2007, 53:67-74.

42. Wu C, Lu Y: High-titre retroviral vector system for efficient gene delivery into human and mouse cells of haematopoietic and lymphocytic lineages. J Gen Virol 2010, 91:1909-1918.

43. Beaudoin GM 3rd, Lee SH, Singh D, Yuan Y, Ng YG, Reichardt LF, Arikkath J: Culturing pyramidal neurons from the early postnatal mouse hippocampus and cortex. Nat Protoc 2012, 7:1741-1754.

44. Mizuguchi H, Xu Z, Ishii-Watabe A, Uchida E, Hayakawa T: IRES-dependent second gene expression is significantly lower than cap-dependent first gene expression in a bicistronic vector. Mol Ther 2000, 1:376-382.

45. Mondal D, Williams CA, Ali M, Eilers M, Agrawal KC: The HIV-1 Tat protein selectively enhances CXCR4 and inhibits CCR5 expression in megakaryocytic K562 cells. Exp Biol Med (Maywood) 2005, 230:631-644.

46. Agrawal L, Louboutin JP, Strayer DS: Preventing HIV-1 Tat-induced neuronal apoptosis using antioxidant enzymes: mechanistic and therapeutic implications. Virology 2007, 363:462-472.

47. Minagar A, Shapshak P, Fujimura R, Ownby R, Heyes M, Eisdorfer C: The role of macrophage/microglia and astrocytes in the pathogenesis of three neurologic disorders: HIV-associated dementia, Alzheimer disease, and multiple sclerosis. J Neurol Sci 2002, 202:13-23.

48. Mind Exchange Working G: Assessment, diagnosis, and treatment of HIVassociated neurocognitive disorder: a consensus report of the mind exchange program. Clin Infect Dis 2013, 56:1004-1017.

49. Apolloni A, Hooker CW, Mak J, Harrich D: Human immunodeficiency virus type 1 protease regulation of tat activity is essential for efficient reverse transcription and replication. J Virol 2003, 77:9912-9921.

50. Harrich D, McMillan N, Munoz L, Apolloni A, Meredith L: Will diverse Tat interactions lead to novel antiretroviral drug targets? Curr Drug Targets 2006, 7:1595-1606

51. Peruzzi F: The multiple functions of HIV-1 Tat: proliferation versus apoptosis. Front Biosci 2006, 11:708-717.

52. Bertrand SJ, Aksenova MV, Mactutus CF, Booze RM: HIV-1 Tat protein variants: critical role for the cysteine region in synaptodendritic injury. Exp Neurol 2013, 248:228-235.

53. Rosen CA, Sodroski JG, Goh WC, Dayton Al, Lippke J, Haseltine WA: Posttranscriptional regulation accounts for the trans-activation of the human T-lymphotropic virus type III. Nature 1986, 319:555-559.

54. Barre-Sinoussi F, Chermann JC, Rey F, Nugeyre MT, Chamaret S, Gruest J, Dauguet C, Axler-Blin C, Vezinet-Brun F, Rouzioux C, Rozenbaum W,
Montagnier L: Isolation of a T-lymphotropic retrovirus from a patient at risk for acquired immune deficiency syndrome (AIDS). Science 1983, 220:868-871.

55. Aksenova MV, Aksenov MY, Adams SM, Mactutus CF, Booze RM: Neuronal survival and resistance to HIV-1 Tat toxicity in the primary culture of rat fetal neurons. Exp Neurol 2009, 215:253-263.

56. Samikkannu T, Rao KV, Gandhi N, Saxena SK, Nair MP: Human immunodeficiency virus type 1 clade $B$ and $C$ Tat differentially induce indoleamine 2,3-dioxygenase and serotonin in immature dendritic cells: Implications for neuroAIDS. J Neurovirol 2010, 16:255-263.

57. Mishra M, Vetrivel S, Siddappa NB, Ranga U, Seth P: Clade-specific differences in neurotoxicity of human immunodeficiency virus-1 B and C Tat of human neurons: significance of dicysteine C30C31 motif. Ann Neurol 2008, 63:366-376.

58. Rao VR, Sas AR, Eugenin EA, Siddappa NB, Bimonte-Nelson H, Berman JW, Ranga U, Tyor WR, Prasad VR: HIV-1 clade-specific differences in the induction of neuropathogenesis. J Neurosci 2008, 28:10010-10016.

59. Li W, Huang Y, Reid R, Steiner J, Malpica-Llanos T, Darden TA, Shankar SK, Mahadevan A, Satishchandra P, Nath A: NMDA receptor activation by HIV-Tat protein is clade dependent. J Neurosci 2008, 28:12190-12198.

60. Gandhi N, Saiyed Z, Thangavel S, Rodriguez J, Rao KV, Nair MP: Differential effects of HIV type 1 clade $B$ and clade $C$ Tat protein on expression of proinflammatory and antiinflammatory cytokines by primary monocytes. AIDS Res Hum Retroviruses 2009, 25:691-699.

61. Wong JK, Campbell GR, Spector SA: Differential induction of interleukin-10 in monocytes by HIV-1 clade B and clade C Tat proteins. J Biol Chem 2010, 285:18319-18325.

62. Kim BO, Liu Y, Ruan Y, Xu ZC, Schantz L, He JJ: Neuropathologies in transgenic mice expressing human immunodeficiency virus type 1 Tat protein under the regulation of the astrocyte-specific glial fibrillary acidic protein promoter and doxycycline. Am J Pathol 2003, 162:1693-1707.

63. Carey AN, Sypek El, Singh HD, Kaufman MJ, McLaughlin JP: Expression of HIV-Tat protein is associated with learning and memory deficits in the mouse. Behav Brain Res 2012, 229:48-56.

64. Perez A, Probert AW, Wang KK, Sharmeen L: Evaluation of HIV-1 Tat induced neurotoxicity in rat cortical cell culture. J Neurovirol 2001, 7:1-10.

65. Carter PJ: Introduction to current and future protein therapeutics: a protein engineering perspective. Exp Cell Res 2011, 317:1261-1269.

66. Czajkowsky DM, Hu J, Shao Z, Pleass RJ: Fc-fusion proteins: new developments and future perspectives. EMBO Mol Med 2012, 4:1015-1028.

67. Suzuki T, Ishii-Watabe A, Tada M, Kobayashi T, Kanayasu-Toyoda T, Kawanishi $T$, Yamaguchi $T$ : Importance of neonatal FcR in regulating the serum halflife of therapeutic proteins containing the Fc domain of human IgG1: a comparative study of the affinity of monoclonal antibodies and Fc-fusion proteins to human neonatal FcR. J Immunol 2010, 184:1968-1976.

68. Lee TY, Tjin Tham Sjin RM, Movahedi S, Ahmed B, Pravda EA, Lo KM, Gillies SD, Folkman J, Javaherian K: Linking antibody Fc domain to endostatin significantly improves endostatin half-life and efficacy. Clin Cancer Res 2008, 14:1487-1493.

69. Jorgensen ML, Friis NA, Just J, Madsen P, Petersen SV, Kristensen P: Expression of single-chain variable fragments fused with the Fc-region of rabbit IgG in Leishmania tarentolae. Microb Cell Fact 2014, 13:9.

70. Carter J, Zhang J, Dang TL, Hasegawa H, Cheng JD, Gianan I, O'Neill JW, Wolfson M, Siu S, Qu S, Meininger D, Kim H, Delaney J, Mehlin C: Fusion partners can increase the expression of recombinant interleukins via transient transfection in 2936E cells. Protein Sci 2010, 19:357-362.

71. Klein JS, Gnanapragasam PN, Galimidi RP, Foglesong CP, West AP Jr, Bjorkman PJ: Examination of the contributions of size and avidity to the neutralization mechanisms of the anti-HIV antibodies b12 and 4E10. Proc Natl Acad Sci U S A 2009, 106:7385-7390.

72. Morgan JR, LeDoux JM, Snow RG, Tompkins RG, Yarmush ML: Retrovirus infection: effect of time and target cell number. J Virol 1995, 69:6994-7000

73. Englund U, Ericson C, Rosenblad C, Mandel RJ, Trono D, Wictorin K, Lundberg C: The use of a recombinant lentiviral vector for ex vivo gene transfer into the rat CNS. Neuroreport 2000, 11:3973-3977.

74. Gavegnano C, Kennedy EM, Kim B, Schinazi RF: The impact of macrophage nucleotide pools on HIV-1 reverse transcription, viral replication, and the development of novel antiviral agents. Mol Biol Int 2012, 2012:625983.

75. Diamond TL, Roshal M, Jamburuthugoda VK, Reynolds HM, Merriam AR, Lee KY, Balakrishnan M, Bambara RA, Planelles V, Dewhurst S, Kim B: 
Macrophage tropism of HIV-1 depends on efficient cellular dNTP utilization by reverse transcriptase. J Biol Chem 2004, 279:51545-51553.

76. Jamburuthugoda VK, Chugh P, Kim B: Modification of human immunodeficiency virus type 1 reverse transcriptase to target cells with elevated cellular dNTP concentrations. J Biol Chem 2006, 281:13388-13395.

77. Deglon N, Tseng JL, Bensadoun JC, Zurn AD, Arsenijevic Y, Pereira De Almeida L, Zufferey R, Trono D, Aebischer P: Self-inactivating lentiviral vectors with enhanced transgene expression as potential gene transfer system in Parkinson's disease. Hum Gene Ther 2000, 11:179-190.

78. Lu-Nguyen NB, Broadstock M, Schliesser MG, Bartholomae C, von Kalle C, Schmidt M, Yáñez-Muñoz RJ: Transgenic expression of human glial cell line-derived neurotrophic factor (hGDNF) from integration-deficient lentiviral vectors is neuroprotective in a rodent model of Parkinson's disease. Hum Gene Ther 2014, 25(7):631-641.

79. Ericson C, Georgievska B, Lundberg C: Ex vivo gene delivery of GDNF using primary astrocytes transduced with a lentiviral vector provides neuroprotection in a rat model of Parkinson's disease. Eur J Neurosci 2005, 22:2755-2764

80. Dou H, Grotepas CB, McMillan JM, Destache CJ, Chaubal M, Werling J, Kipp J, Rabinow B, Gendelman HE: Macrophage delivery of nanoformulated antiretroviral drug to the brain in a murine model of neuroAIDS. J Immunol 2009, 183:661-669.

81. Ji KA, Yang MS, Jeong HK, Min KJ, Kang SH, Jou I, Joe EH: Resident microglia die and infiltrated neutrophils and monocytes become major inflammatory cells in lipopolysaccharide-injected brain. Glia 2007, 55:1577-1588

82. Lebson L, Nash K, Kamath S, Herber D, Carty N, Lee DC, Li Q, Szekeres K, Jinwal U, Koren J, Dickey CA, Gottschall PE, Morgan D, Gordon MN: Trafficking CD11b-positive blood cells deliver therapeutic genes to the brain of amyloid-depositing transgenic mice. J Neurosci 2010, 30:9651-9658

83. Wang H, Sun J, Goldstein H: Human immunodeficiency virus type 1 infection increases the in vivo capacity of peripheral monocytes to cross the blood-brain barrier into the brain and the in vivo sensitivity of the blood-brain barrier to disruption by lipopolysaccharide. J Virol 2008 $82: 7591-7600$

84. Miron VE, Franklin RJ: Macrophages and CNS remyelination. J Neurochem 2014, 130(2):165-171.

85. Prinz $\mathrm{M}$, Tay $\mathrm{TL}$, Wolf $\mathrm{Y}$, Jung S: Microglia: unique and common features with other tissue macrophages. Acta Neuropathol 2014, 128(3):319-331.

86. McMillan J, Batrakova E, Gendelman HE: Cell delivery of therapeutic nanoparticles. Prog Mol Biol Transl Sci 2011, 104:563-601.

87. Biju K, Zhou Q, Li G, Imam SZ, Roberts JL, Morgan WW, Clark RA, Li S: Macrophage-mediated GDNF delivery protects against dopaminergic neurodegeneration: a therapeutic strategy for Parkinson's disease. $\mathrm{Mol}$ Ther 2010, 18:1536-1544

88. Ensoli B, Cafaro A: Control of viral replication and disease onset in cynomolgus monkeys by HIV-1 TAT vaccine. J Biol Regul Homeost Agents 2000, 14:22-26.

89. Re MC, Gibellini D, Furlini G, Vignoli M, Vitone F, Bon I, La Placa M: Relationships between the presence of anti-Tat antibody, DNA and RNA viral load. New Microbiol 2001, 24:207-215.

90. Richardson MW, Mirchandani J, Duong J, Grimaldo S, Kocieda V, Hendel H, Khalili K, Zagury JF, Rappaport J: Antibodies to Tat and Vpr in the GRIV cohort: differential association with maintenance of long-term nonprogression status in HIV-1 infection. Biomed Pharmacother 2003, 57:4-14.

91. Palfi S, Gurruchaga JM, Ralph GS, Lepetit H, Lavisse S, Buttery PC, Watts C, Miskin J, Kelleher M, Deeley S, Iwamuro H, Lefaucheur JP, Thiriez C, Fenelon G, Lucas C, Brugières P, Gabriel I, Abhay K, Drouot X, Tani N, Kas A, Ghaleh B, Le Corvoisier P, Dolphin P, Breen DP, Mason S, Guzman NV, Mazarakis ND, Radcliffe PA, Harrop R, et al: Long-term safety and tolerability of ProSavin, a lentiviral vector-based gene therapy for Parkinson's disease: a dose escalation, open-label, phase 1/2 trial. Lancet 2014, 383(9923):1138-1146.

92. Sierra-Filardi E, Nieto C, Dominguez-Soto A, Barroso R, Sanchez-Mateos $P$, Puig-Kroger A, Lopez-Bravo M, Joven J, Ardavin C, Rodriguez-Fernandez JL, Sánchez-Torres C, Mellado M, Corbí AL: CCL2 shapes macrophage polarization by GM-CSF and M-CSF: identification of CCL2/CCR2dependent gene expression profile. J Immunol 2014, 192(8):3858-3867.

93. Jaguin M, Houlbert N, Fardel O, Lecureur V: Polarization profiles of human M-CSF-generated macrophages and comparison of M1-markers in classically activated macrophages from GM-CSF and M-CSF origin. Cell Immunol 2013, 281:51-61.

94. Biswas SK, Mantovani A: Macrophage plasticity and interaction with lymphocyte subsets: cancer as a paradigm. Nat Immunol 2010, 11:889-896

95. Cassol E, Cassetta L, Alfano M, Poli G: Macrophage polarization and HIV-1 infection. J Leukoc Biol 2010, 87:599-608.

96. Mantovani A, Sica A, Sozzani S, Allavena P, Vecchi A, Locati M: The chemokine system in diverse forms of macrophage activation and polarization. Trends Immunol 2004, 25:677-686.

97. Grant RS, Naif H, Thuruthyil SJ, Nasr N, Littlejohn T, Takikawa O, Kapoor V: Induction of indolamine 2,3-dioxygenase in primary human macrophages by human immunodeficiency virus type 1 is strain dependent. J Virol 2000, 74:4110-4115.

98. Afkhami-Goli A, Liu SH, Zhu Y, Antony JM, Arab H, Power C: Dual lentivirus infection potentiates neuroinflammation and neurodegeneration: viral copassage enhances neurovirulence. J Neurovirol 2009, 15:139-152.

99. Boasso A, Vaccari M, Hryniewicz A, Fuchs D, Nacsa J, Cecchinato V, Andersson J, Franchini G, Shearer GM, Chougnet C: Regulatory T-cell markers, indoleamine 2,3-dioxygenase, and virus levels in spleen and gut during progressive simian immunodeficiency virus infection. J Virol 2007, 81:11593-11603.

100. Maneglier B, Malleret B, Guillemin GJ, Spreux-Varoquaux O, Devillier P, Rogez-Kreuz C, Porcheray F, Therond P, Dormont D, Clayette P: Modulation of indoleamine-2,3-dioxygenase expression and activity by HIV-1 in human macrophages. Fundam Clin Pharmacol 2009, 23:573-581.

101. Fu X, Lawson MA, Kelley KW, Dantzer R: HIV-1 Tat activates indoleamine 2,3 dioxygenase in murine organotypic hippocampal slice cultures in a p38 mitogen-activated protein kinase-dependent manner. J Neuroinflammation 2011, 8:88,

102. Samikkannu T, Saiyed ZM, Rao KV, Babu DK, Rodriguez JW, Papuashvili MN, Nair MP: Differential regulation of indoleamine-2,3-dioxygenase (IDO) by HIV type 1 clade B and C Tat protein. AIDS Res Hum Retroviruses 2009, 25:329-335

103. Potula R, Poluektova L, Knipe B, Chrastil J, Heilman D, Dou H, Takikawa O, Munn DH, Gendelman HE, Persidsky Y: Inhibition of indoleamine 2,3dioxygenase (IDO) enhances elimination of virus-infected macrophages in an animal model of HIV-1 encephalitis. Blood 2005, 106:2382-2390.

104. Sei S, Saito K, Stewart SK, Crowley JS, Brouwers P, Kleiner DE, Katz DA, Pizzo PA, Heyes MP: Increased human immunodeficiency virus (HIV) type 1 DNA content and quinolinic acid concentration in brain tissues from patients with HIV encephalopathy. J Infect Dis 1995, 172:638-647.

105. Sardar AM, Reynolds GP: Frontal cortex indoleamine-2,3-dioxygenase activity is increased in HIV-1-associated dementia. Neurosci Lett 1995, 187:9-12.

106. Hryniewicz A, Boasso A, Edghill-Smith Y, Vaccari M, Fuchs D, Venzon D, Nacsa J, Betts MR, Tsai WP, Heraud JM, Beer B, Blanset D, Chougnet C, Lowy I, Shearer GM, Franchini G: CTLA-4 blockade decreases TGF-beta, IDO, and viral RNA expression in tissues of SIVmac251-infected macaques. Blood 2006, 108:3834-3842.

107. Suh HS, Zhao ML, Rivieccio M, Choi S, Connolly E, Zhao Y, Takikawa O, Brosnan CF, Lee SC: Astrocyte indoleamine 2,3-dioxygenase is induced by the TLR3 ligand poly(l:C): mechanism of induction and role in antiviral response. J Virol 2007, 81:9838-9850.

108. Cassetta L, Kajaste-Rudnitski A, Coradin T, Saba E, Della Chiara G, Barbagallo M, Graziano F, Alfano M, Cassol E, Vicenzi E, Poli G: M1 polarization of human monocyte-derived macrophages restricts pre and postintegration steps of HIV-1 replication. AIDS 2013, 27:1847-1856.

doi:10.1186/s12974-014-0195-2

Cite this article as: Kang et al:: Anti-tat Hutat2:Fc mediated protection against tat-induced neurotoxicity and HIV-1 replication in human monocyte-derived macrophages. Journal of Neuroinflammation 2014 11:195. 